\title{
The Price of Really Clean Water: Combining Nanofiltration with Granular Activated Carbon and Anion Exchange Resins for the Removal of Per- And Polyfluoralkyl Substances (PFASs) in Drinking Water Production
}

\author{
Vera Franke,* Malin Ullberg,* Philip McCleaf, Maria Wålinder, Stephan J. Köhler, and Lutz Ahrens
}

Cite This: ACS EST Water 2021, 1, 782-795

Read Online

ACCESS |

Wll Metrics \& More

Article Recommendations

Supporting Information

ABSTRACT: The removal of per- and polyfluoroalkyl substances (PFASs) presents a challenge for drinking water providers. Guidelines for PFAS concentrations in final drinking water are regularly updated to ever-decreasing values, and conventional drinking water treatment plants are not designed to remove PFASs. Currently, the most frequently used removal technique, adsorption to granular activated carbon (GAC), is often considered challenging. High-pressure membranes, such as nanofiltration (NF), have been shown to remove PFASs efficiently. However, the creation of a waste stream comprised of at least $10 \%$ of the feedwater volume is recognized as a major drawback of this technique. In this study, a NF pilot plant was operated at a

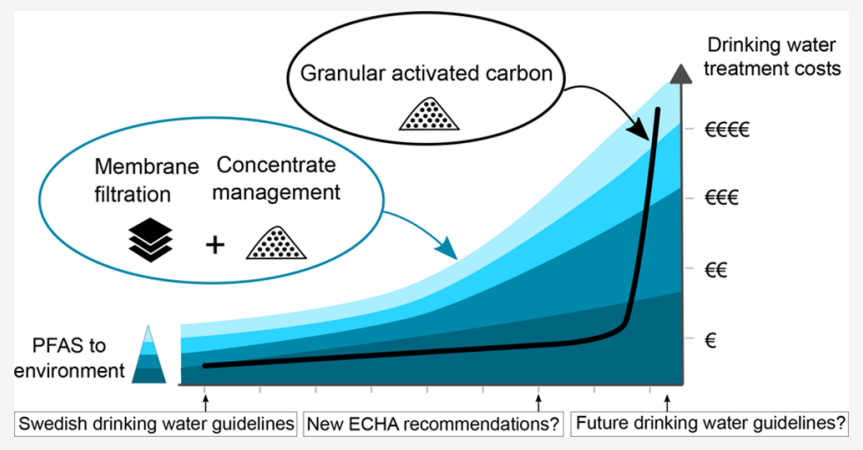
drinking water treatment plant in the city of Uppsala, Sweden, for six months. NF removed up to $>98 \%$ of PFASs and fulfilled other water quality targets, such as the removal of uranium-238, dissolved organic carbon (DOC), and mineral hardness from the raw water. The concentrate from the pilot plant was treated with two different GAC materials and two different anion exchange (AIX) resins in column tests, where the superior performance of AIX over GAC was observed in terms of PFAS removal. PFAS adsorption curves for GAC were found to superimpose each other for the two water types if normalized to the specific throughput of DOC. The application of the freely available PHREEQC model revealed improvement possibilities in terms of resin properties. A cost analysis using the column test results compared GAC filtration to the combination of NF with adsorption materials. Treatment costs were found to be largely dependent on the PFAS drinking water treatment goals and concentrate discharge requirements, which highlight the economic consequences of prevailing guidelines for drinking water and discharge to the environment. The results of this study provide both the scientific community as well as drinking water providers with important insights into the application of NF for PFAS removal during drinking water treatment as well as that mechanistic and economic aspects of NF treatment and the management of the resulting concentrate.

KEYWORDS: drinking water, nanofiltration, per- and polyfluoroalkyl substances (PFAS), natural organic carbon, granular activated carbon (GAC), anion exchange resins (AIX)

\section{INTRODUCTION}

The group of per- and polyfluoroalkyl substances (PFASs) is a diverse family of more than 4700 different chemical compounds with a large range of physicochemical properties. ${ }^{1}$ PFASs are defined as chemical compounds with at least one perfluorocarbon moiety $\left(-\mathrm{CF}_{2}-\right)$, where polyfluoroalkyl compounds contain partly fluorinated alkyl chains and perfluoroalkyl substances contain fully fluorinated carbon chains. ${ }^{2,3}$ Many PFASs have both hydrophobic and oleophobic properties, and studies have shown that they are able to undergo long-range transport and accumulate in organisms. ${ }^{4,5}$ Their extreme persistence together with the established correlations of PFAS exposure to various types of cancer and other adverse health effects make many of them substances of very high concern (SVHC). Various countries currently regulate PFASs. ${ }^{6}$ PFASs have been produced since the 1950s, and their applications seem endless, covering a wide range of industrial and consumer products in both essential and nonessential applications. ${ }^{7-9}$ While exposure via PFAScontaining products such as dental floss, water repellent textiles, or ski waxes presents an undisguised route of exposure

Received: September 3, 2020

Revised: December 12, 2020

Accepted: December 14, 2020

Published: January 29, 2021

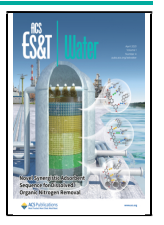


for humans, more deceptive pathways include contaminated food or drinking water. ${ }^{10}$ Along with emissions that arise during the manufacture of PFASs and PFAS-containing products, wastewater effluents, and leachate from landfills, the use of PFAS-containing fire-fighting foam has led to the contamination of numerous sites and impacted both groundwater and surface waters around the globe. ${ }^{8,11,12}$ Drinking water produced from contaminated water sources can be a dominant source for human exposure to PFASs, ${ }^{13}$ as conventional drinking water treatment techniques are often insufficient for the removal of PFASs from water. ${ }^{14-17}$ Common practice for removal of PFASs in drinking water treatment is filtration through fresh granular activated carbon (GAC) materials. ${ }^{15,16,18-20}$ The adsorption of PFASs to GAC is, however, dependent on the compounds' chain length and functional group; the breakthrough of short-chain perfluorocarboxylic acids (PFCAs) and perfluorosulfonic acids (PFSAs) occurs rather quickly, making GAC filtration a challenging technique for long-term efficient PFAS removal. $^{21-23}$ Similarly, anion exchange (AIX) resins have been shown to be an effective method for PFAS removal, with a greater adsorption capacity than GAC but some of the same functional and chain length removal characteristics. ${ }^{22,24-28}$ More recently, membrane processes have gained attention as they function as both microbiological and chemical barriers in drinking water production, with size-exclusion as their main removal mechanism. ${ }^{29}$ Among these, nanofiltration (NF) is an established water treatment method that can reliably target several treatment goals, including the removal of organic matter to control disinfection byproduct formation as well as the removal of mineral hardness, organic micropollutants, and even pathogens. ${ }^{29-31}$ While high-pressure membrane techniques such as NF and reverse osmosis have long been identified as exceptionally effective for removing a broad range of PFASs from water, ${ }^{17,28,32-34}$ the management of the membrane concentrate represents a significant challenge both practically and economically. ${ }^{30}$ While GAC, AIX, and NF filtration have been shown to successfully remove PFASs, little research has been done on the economic implications of these processes.

In this study, a NF pilot plant was employed at the drinking water treatment plant (DWTP) Bäcklösa in the city of Uppsala, Sweden. The suitability of two different GAC materials and two different AIX resins for the removal of PFASs from a contaminated raw water source and the NF concentrate were evaluated. Continuous-flow experiments were conducted in pilot-scale column tests, with up to 50000 bed volumes treated. The primary objective of this study was to compare the different adsorption materials in regard to their ability to remove PFASs from a NF concentrate. The influence of dissolved organic carbon (DOC) on PFAS adsorption on GAC was investigated. A previously developed code using the reactive transport model PHREEQC ${ }^{35}$ was successfully applied to explain breakthrough patterns through the best-performing materials, taking into account PFAS properties and various water quality parameters. The model allowed the study of the effect of different binding constants as well as the binding capacity. Finally, a cost analysis elucidates the relative operations cost of GAC and AIX for NF concentrate treatment at the Bäcklösa plant by comparing the combination of NF with AIX or GAC for concentrate treatment against solely using GAC filtration, which is currently the case for PFAS removal at the plant. This study thus provides valuable information on economical aspects connected to the combination of NF and adsorption materials to aid water purveyors in decision making on treatment process selection and cost implications.

\section{MATERIALS AND METHODS}

2.1. Water Quality. Raw water for the experiments was diverted from a groundwater entering DWTP Bäcklösa in Uppsala, Sweden. This water contains approximately 100-200 ng $\mathrm{L}^{-1} \sum$ PFAS (Table S.1 in the SI). Of the 32 PFASs measured for the nanofiltration process (see Section 2.6 and Table S.2 in the SI), six ( $\mathrm{C}_{5}^{\mathrm{F}}$ and $\mathrm{C}_{7}^{\mathrm{F}}$ PFCAs PFHxA and PFOA, respectively; $\mathrm{C}_{4}^{\mathrm{F}}, \mathrm{C}_{5}^{\mathrm{F}}, \mathrm{C}_{6}^{\mathrm{F}}$, and $\mathrm{C}_{8}^{\mathrm{F}}$ PFSAs PFBS, PFPeS, PFHxS, and PFOS, respectively) and ten $\left(\mathrm{C}_{3}^{\mathrm{F}}, \mathrm{C}_{4}^{\mathrm{F}}, \mathrm{C}_{5}^{\mathrm{F}}, \mathrm{C}_{6}^{\mathrm{F}}\right.$, and $\mathrm{C}_{7}^{\mathrm{F}}$ PFCAs PFBA, PFPeA, PFHxA, PFHpA, and PFOA, respectively; $\mathrm{C}_{4}^{\mathrm{F}}, \mathrm{C}_{5}^{\mathrm{F}}, \mathrm{C}_{6}^{\mathrm{F}}, \mathrm{C}_{7}^{\mathrm{F}}$, and $\mathrm{C}_{8}^{\mathrm{F}}$ PFSAs PFBS, PFPeS, PFHxS, PFHpS, and PFOS, respectively) PFASs were frequently detected in the feedwater for the nanofiltration plant (i.e., raw water) and concentrate, respectively. Average values for the water quality parameters that were continuously monitored during the column experiments are summarized in Table 1.

Table 1. Average Values \pm Standard Deviation for Various Water Quality Parameters and PFASs Detected during the Column Experiment ${ }^{a}$

\begin{tabular}{llcc} 
parameter & \multicolumn{1}{c}{ unit } & raw water & NF concentrate \\
PFHxA & $\mathrm{ng} \mathrm{L}^{-1}$ & $4.5 \pm 4.8$ & $25 \pm 17$ \\
PFOA & $\mathrm{ng} \mathrm{L}^{-1}$ & $7.4 \pm 3.0$ & $22 \pm 5.0$ \\
PFBS & $\mathrm{ng} \mathrm{L}^{-1}$ & $11 \pm 2.3$ & $33 \pm 7.7$ \\
PFPeS & $\mathrm{ng} \mathrm{L}^{-1}$ & $17 \pm 6.7$ & $59 \pm 16$ \\
PFHpS & $\mathrm{ng} \mathrm{L}^{-1}$ & $<\mathrm{LOQ}$ & $8.2 \pm 2.2$ \\
PFHxS & $\mathrm{ng} \mathrm{L}^{-1}$ & $78 \pm 22$ & $300 \pm 80$ \\
PFOS & $\mathrm{ng} \mathrm{L}^{-1}$ & $40 \pm 17$ & $130 \pm 44$ \\
$\sum$ PFAS & $\mathrm{ng} \mathrm{L}^{-1}$ & $160 \pm 53$ & $570 \pm 160$ \\
DOC & $\mathrm{mg} \mathrm{L}^{-1}$ & $3.0 \pm 0.27$ & $14 \pm 0.5$ \\
$\mathrm{UV}$ & & $0.27 \pm 0.02$ & $1.34 \pm 0.17$ \\
Alkalinity & $\mathrm{per} \mathrm{5} \mathrm{cm} \mathrm{mg} \mathrm{L}^{-1}$ as CaCO & $130 \pm 5$ & $970 \pm 43$ \\
$\mathrm{SO}_{4}^{2-}$ & $\mathrm{mg} \mathrm{L}^{-1}$ & $41 \pm 0.5$ & $200 \pm 5.2$ \\
$\mathrm{Cl}^{-}$ & $\mathrm{mg} \mathrm{L}^{-1}$ & $38 \pm 0.1$ & $100 \pm 4.2$ \\
$\mathrm{~F}^{-}$ & $\mathrm{mg} \mathrm{L}^{-1}$ & $1.2 \pm 0.05$ & $3.90 \pm 0.1$
\end{tabular}

${ }^{a}$ Note that for deriving the average concentration of the parameters values below the respective limits of quantification (LOQ) were replaced with a 0.5 LOQ $i$ DOC, dissolved organic carbon.

2.2. Nanofiltration. The nanofiltration pilot plant consisted of a two-stage process using six spiral-wound membranes (NF90-400; Dow Filmtech Membranes) in the first stage and three spiral wound membranes in the second stage (NF270-400; Dow Filmtech Membranes). The operating feedwater flow rate was $8 \mathrm{~m}^{3} \mathrm{hr}^{-1}$, which was first pumped through a $5 \mu \mathrm{m}$ prefilter consisting of seven elements (GE Infrastructure Water and Process Technology Purtrex 530 filter) to remove solids in the raw water before entering the NF unit (see Figure S.1 in the SI for details). Concentrate recirculation to the feedwater was provided at $6 \mathrm{~m}^{3} \mathrm{hr}^{-1}$. This process design was selected so as to attain a water hardness goal of $6^{\circ} \mathrm{dH}\left(107 \mathrm{mg} \mathrm{L}^{-1}\right.$ as $\left.\mathrm{CaCO}_{3}\right)$ in the permeate, thus enabling all the water to pass through the membrane in order to provide a microbiological barrier and avoid mixing a bypass stream with the concentrate to achieve the final water hardness goal. This process is under consideration for a new full-scale treatment plant for the city of Uppsala, Sweden. The NF 
process was also selected to provide the removal of PFAS, uranium-238, DOC, and bromide from the raw water. The pilot was operated from March 18, 2019 to July 5, 2019 with an $80 \%$ recovery and from July 5, 2019 to September 16, 2019 with a $70 \%$ recovery, and the transmembrane pressure varied from 5 to 8 bar. Antiscalant (Ameroyal 363 Ashland Corp) was added to the feedwater to provide a concentration of $3.0 \mathrm{~g} \mathrm{~m}^{-3}$ in the feedwater before entering the NF. Samples were taken for the NF process feedwater, stage 1 permeate, stage 2 permeate, total permeate, and concentrate (Figure 1). A

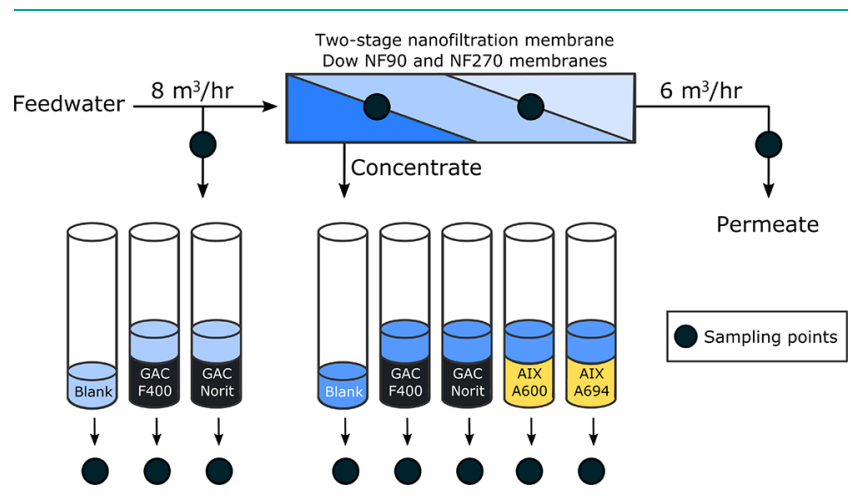

Figure 1. Experimental setup of the column experiments. Information on feedwater and permeate pressure are in regard to an operation scenario at $80 \%$ recovery; NF, nanofiltration; GAC, granular activated carbon; AIX, anion exchange resin; F400, Filtrasorb 400; Norit, Norit 2140W; A600, Purolite A600; A694, Purofine PFA694.

detailed summary of all measured water quality parameters and PFASs can be found in Table S.1 in the SI. Flow rates for the feedwater, recycle, and concentrate along with the inlet and outlet pressure and water temperature were continuously monitored and automatically logged.

2.3. Adsorption Materials. 2.3.1. Granular Activated Carbon. Two commercially available GAC materials, Filtrasorb 400 (Calgon Carbon Corporation, Feluy, Belgium; effective size of $0.55-0.75 \mathrm{~mm}$, surface area of $1050 \mathrm{~m}^{2} \mathrm{~g}^{-1}$, and iodine number of $1000 \mathrm{mg} \mathrm{g}^{-1}$ ) and Norit $1240 \mathrm{~W}$ (Norit Nederland BV, Amersfoort, The Netherlands; effective size of $0.65 \mathrm{~mm}$, surface area of $1150 \mathrm{~m}^{2} \mathrm{~g}^{-1}$, and iodine number of $1020 \mathrm{mg}$ $\mathrm{g}^{-1}$ ) were applied. The main difference, and why it is interesting to compare these two, is that the Filtrasorb 400 material is prepared from steam-activated bituminous coal that was pulverized and reagglomerated whereas Norit $1240 \mathrm{~W}$ is prepared from steam-activated coal. Reagglomerated coals tend to be homogeneously activated throughout, making it a competitive material for the adsorption of PFASs and other micropollutants.

2.3.2. Anion Exchange Resins. The two AIX materials used in this study were received from Purolite Corporation (King of Prussia, PA, USA). The Purolite A600 is a Type I strong-base anion resin with quaternary amino functional groups (polystyrene cross-linked with divinylbenzene; "gel-type" resin).

The Purofine PFA694 resin is also a polystyrenic resin (polystyrene cross-linked with divinylbenzene), and the manufacturers describe the functional group as "complex amino" (for more details see the manufacturers data sheets ${ }^{36,37}$ and Table S.4 in the SI). Previous experiments had identified the Purolite A600 resin as superior to the GAC material Filtrasorb 400 in terms of total PFAS uptake. ${ }^{28}$ This study aimed at comparing the aforementioned resin with a material specifically designed for PFAS adsorption (Purofine PFA694).

2.4. Experimental Setup. Membrane feedwater and concentrate flowed continually to two separate $600 \mathrm{~L}$ polyethylene holding tanks (Icorene, Montereau, France). The tanks were allowed to overflow to ensure a constantly fresh supply of both water types to the columns. Columns used in this study were made from acrylic glass $(5.5 \mathrm{~cm}$ inner diameter and $6.4 \mathrm{~cm}$ outer diameter) and were $2.5 \mathrm{~m}$ long with a stainless steel mesh $(0.50 \times 0.22 \mathrm{~mm}$ openings, Stockholms Plåt och Gummiperforering, Västerhaninge, Sweden) at the bottom. The columns were filled with $500 \mathrm{~mL}$ of the washed and presoaked adsorption materials, which were washed down with a small quantity of the respective water type. Blank columns $(n=2)$ without any adsorption material were added for data quality control to account for potential heterogeneously distributed concentrations in the tanks and as well as the potential adsorption of compounds to the column walls. Water exiting the blank columns thus served as the reference water being treated by columns filled with the adsorption material at a specific sampling occasion (i.e "ingoing" water). In total, three columns were connected to the feedwater tank and five columns were connected to the concentrate tank (Figure 1). Peristaltic pumps (Watson-Marlow, type 520S) were used to pump water from the reservoir tanks through marprene tubings (Watson-Marlow Limited, Falmouth, UK) to the respective columns at a flow-rate of $100 \mathrm{~mL} \mathrm{~min}^{-1}$ (5 min empty bed contact time; EBCT).

2.5. Analysis of Organic Matter and Inorganic Salt Contents. For the analysis of the organic matter content, 20 $\mathrm{mL}$ samples were acidified with $200 \mu \mathrm{L}$ of $4 \mathrm{M}$ hydrochloric acid and subsequently analyzed using a catalytic combustion analyzer (TOC-VCPH with an ASI-V auto sampler, Shimadzu). The organic matter determined with this analysis is the nonpurgeable organic carbon (NPOC) fraction, which in this case can be referred to as the total organic carbon (TOC) content. $^{23}$ To determine the true dissolved organic carbon (DOC) fraction of the water types, both the NF concentrate and membrane feedwater were filtered through a $0.45 \mu \mathrm{m}$ syringe filter and compared to unfiltered samples in a preexperiment. As differences between the filtered and unfiltered samples were within the range of measuring uncertainties, the filtration step was omitted for the remaining samples, and the NPOC content determined during analysis is referred to as the DOC concentration. The absorbance of UV light at $254 \mathrm{~nm}$ was determined with a photometer (AvaSpec-ULS3648 highresolution Spectrometer, Avantes). A $5 \mathrm{~cm}$ quartz cuvette was used for the measurements, and EDTA $10 \mathrm{mg} \mathrm{L}^{-1}$ and Milli-Q water were analyzed every 8 samples to control for possible instrument drift.

As the NF concentrate contains a rather high amount of carbonate ions, the routine addition of $200 \mu \mathrm{L}$ of $2 \mathrm{M}$ hydrochloric acid proved to be insufficient for the removal of the full carbonate content in the samples, which was reflected in measured TOC concentrations that were much higher than was probable (Figure S.2a in the SI). Unfortunately, this was only discovered 7 days into the experiment, and measured DOC concentrations for the first six sampling occasions had to be reevaluated. DOC concentrations for these samples were calculated from the data received for the UV absorption (254 $\mathrm{nm}$ ) using linear regression and utilizing the linear relationship between the DOC and the UV absorption at $254 \mathrm{~nm}$. Separate 
regressions were used for AIX and GAC effluents as well as for feedwater (Figure S.2 in the SI). ${ }^{38,39}$

For monitoring breakthrough of alkalinity $\left(\mathrm{mg} \mathrm{L}^{-1}\right.$ as $\left.\mathrm{CaCO}_{3}\right)$, sulfate $\left(\mathrm{SO}_{4}^{2-}\right)$, chloride $\left(\mathrm{Cl}^{-}\right)$, and fluoride $\left(\mathrm{F}^{-}\right)$in the anion exchange columns, water samples were collected in $250 \mathrm{~mL}$ plastic bottles according to the instructions provided by the geochemical laboratory at SLU (accredited by SWEDAC; see Section B in the SI for details).

2.6. PFAS Analysis. Samples describing PFAS concentrations during the NF process were analyzed by ALS Scandinavia. Samples were taken in $250 \mathrm{~mL}$ polypropylene (PP) bottles according to the instructions provided by ALS and stored in the dark at $4{ }^{\circ} \mathrm{C}$ prior shipment to Stockholm. For the analysis performed by ALS Scandinavia (Stockholm, Sweden), ${ }^{40,41} 32$ PFASs were analyzed; see Table S.2 in the SI. Samples taken to monitor PFAS concentrations during the column experiments were subject to an extended list of PFASs and were therefore analyzed at SLU. Samples were collected in precleaned $1 \mathrm{~L} \mathrm{PP}$ bottles and stored at $4{ }^{\circ} \mathrm{C}$ in the dark until analysis at SLU. Water samples were extracted via solid-phase extraction according to a method described earlier; ${ }^{42}$ see also Section B.1 in the SI. Analysis conducted at SLU included a list of 37 target PFASs, including the 11 PFASs listed in the Swedish drinking water guidelines (i.e., PFBS, PFHxS, PFOS, PFBA, PFPeA, PFHxA, PFHpA, PFOA, PFNA, PFDA, and 6:2 FTSA). ${ }^{43}$ All analytical standards for the analysis at SLU were purchased from Wellington Laboratories (Guelph, Canada). For a list of the compounds analyzed for the adsorption experiments, including detailed chemical nomenclature, quantification limits, and the association of native compounds with mass-labeled internal standards, see Table S.5 in the SI. An ultraperformance liquid chromatography tandem mass spectrometer (UPLC-MS/MS; TSQ Quantiva, Thermo Fisher Scientific, San Jose, CA) equipped with Thermo Scientific Dionex UltiMate 3000 Pumps and an an Acquity UPLC BEHC18 analytical column $(100 \times 2.1 \mathrm{~mm}$ inner diameter, $1.7 \mu \mathrm{m}$ particle size; Waters Corporation, Manchester, UK) was used for the PFAS analysis. All Teflon parts of the instrument had been replaced prior to analysis. A trapping column was installed after the mixing chamber (ACQUITY UPLC Column Reversed-Phase $1.7 \mu \mathrm{m}$ Spherical Hybrid, $3 \times 30 \mathrm{~mm}$; Waters Corporation, Manchester, UK) to distinguish sample peaks from possible mobile phase contamination. ACQUITY UPLC BEH C18 VanGuard precolumns (130 A, $1.7 \mu \mathrm{m}, 2.1 \times 5 \mathrm{~mm}$; Waters Corporation, Manchester, UK) were installed prior to both the analytical and the trapping columns. Data were evaluated with the TraceFinder 3.3 software (Thermo Fisher). For details on instrument settings and parameters, a summary of the limits of quantification (LOQs), and analyte transitions, see Tables S.5-S.7 in the SI.

2.7. Quality Control and Quality Assurance. Blank samples for the PFAS analysis were treated in the same manner as real samples. Empty PP sampling bottles were opened at the experiment site and stored at $4{ }^{\circ} \mathrm{C}$ until analysis. The bottles were filled with $0.5 \mathrm{~mL}$ of ultrapure water, and the water was subsequently extracted according to the procedure described above. A set of three blank samples were extracted with each extraction batch of 16 samples.

If a compound was found in the blanks, LOQs (ng L $\mathrm{L}^{-1}$ ) were calculated as described in eq 1

$$
\mathrm{LOQ}=c_{\mathrm{blanks}}+8 \cdot \mathrm{sd}
$$

where $c_{\text {blanks }}$ describes the average concentration $\left(\mathrm{ng} \mathrm{L}^{-1}\right)$ found in the blank samples and sd describes the respective standard deviation. Generally, peaks were only taken into account if the signal-to-noise ratio $(\mathrm{S} / \mathrm{N})$ was $\mathrm{S} / N>10$. Seven-point calibration curves (linear correlation coefficient $R^{2}$ $>0.99$ ) were in the range from 1.0 to $200 \mathrm{ng} \mathrm{mL}{ }^{-1}$ for all compounds, corresponding to a concentration range measured from 2.0 to $400 \mathrm{ng} \mathrm{L}^{-1}$ in the samples. Duplicate samples were extracted for three sampling occasions. Concentrations measured in duplicate samples varied less than $10 \%$ (see Table S.3 in the SI).

2.8. Data Handling. 2.8.1. Description of Measured Breakthrough Data. The water volume treated by the respective materials, $V_{\text {treated }}(\mathrm{L})$, was calculated with the help of eq 2

$$
V_{\text {treated }}=r \cdot t
$$

where $r\left(\mathrm{~L} \min ^{-1}\right)$ is the flow-rate and $t(\mathrm{~min})$ describes the time passed. For better comparability, water volumes treated by the adsorption materials were expressed in the amount of treated bed volumes, $\mathrm{BV}_{\text {treated }}$ (dimensionless)

$$
\mathrm{BV}_{\text {treated }}=\frac{r \cdot t}{V_{a d}}
$$

where $t$ is the experiment time $(\mathrm{min})$ and $V_{a d}(\mathrm{~L})$ is the volume of adsorbent material.

Removal efficiencies, RE (\%), were calculated according to eq 4

$$
\mathrm{RE}=\frac{c_{0}-c}{c_{0}} \cdot 100
$$

where $c_{0}$ and $c$ describe concentrations $\left(\mathrm{ng} \mathrm{L} \mathrm{L}^{-1}\right)$ measured in the water entering and leaving the columns at each sampling occasion, respectively. In cases where compounds were removed to concentrations below the LOQ the RE was determined to be $100 \%$.

Total mass loadings of each compound on the column materials, mass collected $(\mathrm{mg})$, were calculated by integrating the area under the curve of the volume of water treated $V_{\text {treated }}(\mathrm{L})$ vs the mass of the compound collected $\left(c_{\text {collected }}=c_{0}-c\right)$ on the columns

$$
\text { mass }_{\text {collected }}=\int_{t_{1}}^{t_{2}} c_{\text {collected }}(t) \cdot V_{\text {treated }}(t) \mathrm{d} V_{\text {treated }}
$$

The specific throughputs per material mass of DOC ( $\mathrm{mg}$ $\left.\mathrm{g}^{-1}\right)$ and UV $\left((5 \mathrm{~cm})^{-1} \mathrm{~g}^{-1}\right)$ were calculated by multiplying the amount of water treated by the average DOC (or UV) content measured during the course of the experiment. To determine the amount of $\mathrm{BV}_{\text {treated }}$ until a certain discharge goal was reached, a linear change in the removal efficiency was assumed between the two points, during which the discharge goal was reached.

2.8.2. Modeling Reactive Transport Using the PHREEQC Model. The breakthrough of the different inorganic and organic compounds through the AIX resins was modeled using the reactive transport model PHRREQC, which is freely available from the USGS site (ver. 2.17 for Microsoft Windows). ${ }^{44-46}$ The code allows for the simultaneous modeling of chemical equilibrium, kinetic, and sorption reactions in a $1 \mathrm{D}$ segmented cell environment with moving water. The code was used to the model competitive ion exchange of a large number of inorganic and organic solutes 
when water was moving through a $1 \mathrm{D}$ column as a function of a gravity-driven flow. The material was assumed to be homogeneous with respect to its porosity. While dispersion processes were considered, no secondary porosity was assumed, and diffusion into the AIX material was therefore disregarded. Based on the physical dimension of the actual column, the model column was divided into 20 cells each with a length of $1.05 \mathrm{~cm}$ and 0.035 equiv of AIX resin material per cell. The chemical composition of the incoming solution (solution 0) was assumed to be constant throughout the whole run (Table 1). For more details see Section C in the SI.

In the PHRREQC model, ion exchange is modeled with ion exchange equilibria calculations according to the GainesThomas convention. ${ }^{46,47}$ With regard to the exchange of PFAS anions, $\mathrm{PFAS}^{-}$, on an $\mathrm{AIX}$ resin, ${ }^{\circ} Y$, saturated with sodium chloride, the following equation describes the exchange process: ${ }^{35}$

$$
(\mathrm{PFAS})^{-}+\mathrm{Cl}^{\circ} \mathrm{Y} \leftrightarrow(\mathrm{PFAS})^{\circ} \mathrm{Y}+\mathrm{Cl}^{-}
$$

The binding constant $K_{(\mathrm{PFAS}) / \mathrm{Cl}}$ describes the distribution of the relevant chemical species in the solution

$$
K_{(\mathrm{PFAS}) / \mathrm{Cl}}=\frac{\left[(\mathrm{PFAS})^{\circ} \mathrm{Y}\right]\left[\mathrm{Cl}^{-}\right]}{\left[\mathrm{Cl}^{\circ} \mathrm{Y}\right]\left[(\mathrm{PFAS})^{-}\right]}
$$

Binding constants for PFASs, inorganic ions, and DOC originate from an earlier study on a similar experiment with the Purolite A600 resin. ${ }^{35}$ Under the conditions of the short EBCT studied here $(5 \mathrm{~min})$ and a difference in several orders of magnitude concentrations for inorganic anions (mmol) as compared to PFASs (nmol), the exact numerical value for major inorganic substances has only a minor influence on the breakthrough time of PFASs. Breakthrough for major inorganic ions occurred after 1 day as compared to PFASs, which occurred after 100 days or more.

Earlier modeling work indicated that binding constants, dispersion, and the binding capacity are the most critical factors for the breakthrough of PFASs in the Purolite A600 resin material. ${ }^{35}$ The constants derived Wålinder $(2015)^{35}$ are referred to as default values in the following. In the current study, the potential impact on PFAS breakthrough was simulated for a modeling period of 100-250 days by increasing and decreasing the amount of the Purolite A600 material by $25 \%$ in one simulation set and by changing binding constants for two key substances (PFHxA and PFOS) by a factor of 2 (i.e., $0.3 \mathrm{log}$ units) in a second simulation set. Subsequently, binding constants were adjusted by a heuristic approximation to reproduce the behavior of both Purolite A600 and Purofine PFA694 materials.

2.8.3. Economic Analysis. A comparative economic analysis was performed using the performance results from the present experiment to estimate the operations costs of PFAS removal treatment for Bäcklösa DWTP using NF filtration with concentrate treatment using GAC or AIX and additionally as it compared to the operations cost using solely GAC filtration with reactivation. The cost analysis considered various drinking water treatment goals for PFASs and PFAS discharge requirements for the treatment of the NF concentrate. It was assumed that the release of an absolute amount of detected PFASs is the limiting factor for the management of the NF concentrate. It should be noted that the analysis was based on results from the pilot column testing of AIX and GAC material for concentrate treatment and the results of the NF pilot for drinking water treatment at Bäcklösa DWTP using groundwater with the water quality shown in Table S.1 in the SI and is therefore site-specific.

Operations costs for NF filtration were determined for an $80 \%$ recovery based on operation parameters, including energy use for the feedwater, recirculation, and antiscalant dosing pumps; the cost of antiscalant, membranes, particle filter replacement; and the cost of the clean in place (CIP) of the membranes from March 18 to July 5, 2019 (see Section D.1 in the SI). Treatment goals of $90,85,50,25,10$, and $4 \mathrm{ng} \mathrm{L}^{-1}$ $\sum_{11}$ PFAS were used as targeted drinking water treatment goals, and an EBCT of $5 \mathrm{~min}$ was used to determine the amount of bed volumes the absorbents could treat before the treated water reached the designated treatment goal for discharge (discharge goal). Upon reaching the bed volume limit, the GAC was assumed to be regenerated and placed back into operation, while the AIX resin was assumed to be sent to incineration and new resin material would be purchased and placed into operation. For GAC, the operations costs included the purchase of virgin GAC, regeneration, and transportation to and from the Bäcklösa DWTP in Uppsala. For the AIX, the costs include the purchase of new AIX, transport, and the incineration of spent AIX. The electrical cost for pumping water through the GAC or AIX beds was included, and the water, as is the case at Bäcklösa DWTP, was assumed to not require pretreatment before PFAS removal by the GAC or AIX. The resulting estimated costs for concentrate treatment with GAC and AIX as well as costs related to using solely GAC for drinking water treatment can be found in Sections D.2 and D.3 in the SI, respectively.

The cost comparison was based on utilizing NF to provide the permeate with $4 \mathrm{ng} \mathrm{L}^{-1} \sum$ PFAS based on the pilot plant results with concentrate treatment using the lowest unit-cost option for concentrate treatment for each treatment goal, i.e., Purofine PFA694 to achieve discharge from 90 to $50 \mathrm{ng} \mathrm{L}^{-1}$ and AIX Purolite A600 for the goals from 25 to $4 \mathrm{ng} \mathrm{L}^{-1}$ $\sum_{11}$ PFAS. Since the permeate concentration was $4 \mathrm{ng} \mathrm{L^{-1 }}$ $\sum_{11}$ PFAS, a blend of permeate and bypass water $\left(96 \mathrm{ng} \mathrm{L}^{-1}\right.$ $\sum_{11}$ PFAS) was calculated for the purpose of the economic comparison to provide drinking water meeting the treatment goals from 90 to $4 \mathrm{ng} \mathrm{L}{ }^{-1} \sum_{11}$ PFAS for a total production of 7 million $\mathrm{m}^{3} \mathrm{yr}^{-1}$ of drinking water, which is the annual production from Bäcklösa DWTP. Thus, for each drinking water treatment goal a different volume of concentrate requires treatment. This information, along with unit costs and additional information that forms the basis for the cost comparison, are provided in Section D.4 in the SI. The operations cost of GAC treatment of raw water to produce drinking water was calculated in a similar fashions as that for the concentrate treatment and was based on the number of $\mathrm{BV}_{\text {treated }}$ by the Filtrasorb $400 \mathrm{GAC}$ column during the present study until the treated raw water reached the designated treatment goal.

\section{RESULTS AND DISCUSSION}

3.1. Performance of the Nanofiltration Process. As the primary goal of the NF process was to achieve a final mineral hardness content of $6^{\circ} \mathrm{dH}\left(107 \mathrm{mg} \mathrm{L}^{-1}\right.$ as $\left.\mathrm{CaCO}_{3}\right)$ in the permeate, operation parameters were chosen accordingly. The NF pilot provided an average PFAS removal of $>98 \%$ while removing $62 \%$ mineral hardness, 97\% uranium-238, 40\% bromide, and $84 \%$ DOC (Figure 2). For more details on the 
removal performance of the two different stages and a full list of the parameters measured, see Table S.1 in the SI.

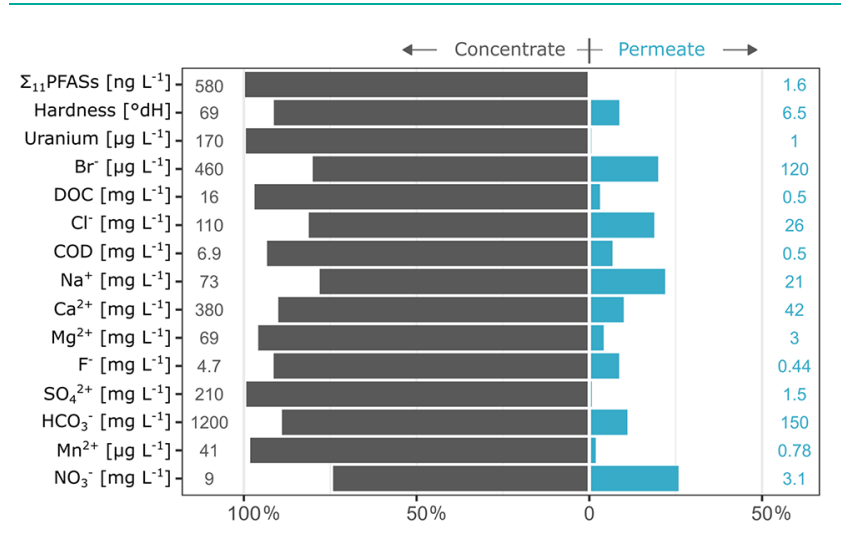

Figure 2. Average percentage of various constituents in the water permeating the membrane and the water rejected by the membrane process. Numbers represent the respective average absolute concentrations.

Numerous studies exist evaluating the influence of various factors on PFAS rejection. Generally, high rejections of PFASs (>90\%) are found for NF membranes with a molecular weight cutoff $\leq 270 \mathrm{Da}^{28,34,48,49}$ While size exclusion is considered the dominating rejection mechanism, other processes such as electrostatic repulsion or hydrophobic-hydrophobic interactions can have an equally important influence on the rejection of small organic molecules. ${ }^{32,50}$ Membrane fouling was observed during this study; however a systematic evaluation of the effects of the membrane type, the feedwater composition, and the fouling on PFAS rejection is not addressed further, and a PFAS removal $>98 \%$ was deemed satisfactory.

3.2. Removal of PFASs from Raw Water and NF Concentrate through Adsorption to GAC and AIX. Figure 3a illustrates the PFAS removal efficiency for the different materials treating raw water and the NF concentrate over the course of the column experiment. Removal efficiency curves of detected PFCAs declined more rapidly than for those for detected PFSAs with the same perfluorocarbon chain length, which is in line with observations reported in earlier studies. ${ }^{15,21,22,28}$ Even though ingoing mass concentrations of the compounds differed for raw water and the NF concentrate, the relative PFAS affinity to the respective adsorption materials seemed to be unaffected. The breakthrough order of the compounds was similar for all GAC and AIX materials evaluated and followed the order PFHxA $>$ PFOA $>$ PFBS $>$ PFPeS $>$ PFHxS $>$ PFHpS $>$ PFOS. PFHxA and PFOA, and PFBS even showed negative removal in some filters, indicating a desorption of these PFASs that has been observed previously. ${ }^{22}$ PFHxA, the shortest PFCA evaluated in the column experiments, showed the fastest decline in the removal efficiency, while PFOS as the longest compound detected was removed best by all materials. One exception was that PFHpS did not break through until the end of the experiments for the Purofine PFA694 resin, which might be related to the low concentration of PFHpS in the NF concentrate being close to the LOQ. In a similar vein, the initially superior removal efficiency for PFHxA in the columns treating raw water can be explained by the relatively low concentrations of this compound found in the raw water (see Table 1). The favored removal of PFSAs compared to PFCAs was especially apparent for the Purofine PFA694 resin, while there was a smaller difference in the removal of PFCAs and PFSAs using Filtrasorb 400, Norit 1240 W, and Purolite A600. Total loadings of the different PFAS groups and DOC during the column experiment and the accumulation of PFAS mass on the column materials can be seen in Figure $3 \mathrm{~b}$ and Figure S.4 in the SI, respectively (for accumulation and loading measured per filter volume, see Figures S.5 and S.6, respectively, in the SI). Generally, AIX resins were observed to have a larger capacity for both PFASs and DOC than the evaluated GAC materials. This has been observed before, and it is hypothesized that this is related to the fact that AIX adsorption sites and functional groups are more specific for PFAS adsorption than those of GAC. ${ }^{17,51-53}$ The greatest total mass loading of PFASs was observed for the Purofine PFA694 resin, where the total mass of analyzed PFASs collected was $37 \mu \mathrm{g} \mathrm{g}^{-1}$ after 48000 $\mathrm{BV}_{\text {treated }}$. When comparing the treatment of raw water to the treatment of the concentrate, both Filtrasorb 400 and Norit $1240 \mathrm{~W}$ adsorbed more PFAS mass from the NF concentrate per mass adsorbent, 15 and $18 \mu \mathrm{g} \mathrm{g}^{-1}$, respectively, than from the more dilute raw water, 8.9 and $8.4 \mu \mathrm{g} \mathrm{g}^{-1}$. This is in line with results reported earlier where both Filtrasorb 400 and Purolite A600 adsorbed more total PFAS mass from the NF concentrate compared to raw water by factors of 2.6 and 4.1, respectively. ${ }^{28}$ Notably, the results suggest that the Filtrasorb 400 material takes up more PFAS mass per gram filter material from the raw water than Norit $1240 \mathrm{~W}$, while the opposite seemed to be true for the treatment of the NF concentrate in this study (Figure $3 b$ ).

3.3. Influence of Organic Matter Content. The removal efficiency for DOC- and UV-absorbing constituents declined more rapidly than the PFAS removal efficiency for all tested absorption materials (Figure 3c). Even though Filtrasorb 400 collected more DOC both when treating raw water and the NF concentrate (38 and $33 \mathrm{mg} \mathrm{g}^{-1}$ filter material) than Norit 1240 $\mathrm{W}$ (25 and $25 \mathrm{mg} \mathrm{g}^{-1}$ ), mass loadings of PFASs were comparable for the two GAC materials when treating raw water, as discussed above (Figure $3 \mathrm{~b}$ ). The Norit $1240 \mathrm{~W}$ material was able to take up more absolute PFAS mass $(18 \mu \mathrm{g}$ $\left.\mathrm{g}^{-1}\right)$ from the NF concentrate than the Filtrasorb $400(15 \mu \mathrm{g}$ $\mathrm{g}^{-1}$ ), which could be due to the lower DOC loading on the filter. Curiously, it seemed that the GAC material Filtrasorb 400 captured more DOC from the feedwater than from the NF concentrate. The rate of decrease in the DOC removal efficiency was less for the GAC materials treating raw water than that for GAC treating the NF concentrate (Figure 3c). When DOC measurements were stopped at approximately $19000 \mathrm{BV}_{\text {treated }}$, the total breakthough of DOC (0\% removal efficiency) had not been reached for the Filtrasorb 400 and Norit 1240 W columns treating raw water. The total breakthrough for DOC was further not captured for the AIX columns treating the NF concentrate (Figure 3c). Breakthrough for the UV-absorbing constituents and the total DOC correlated in all cases (Figure S.2 in the SI). Interestingly, AIX resins had a higher capacity for UV-absorbing constituents than for the total DOC, as can be seen from the breakthrough curves shown in Figure 3c. This preferential uptake of the UV light-absorbing fractions was observed before for other AIX materials and can be explained by a higher affinity of AIX for the aromatic fractions of the DOC compared to other fractions. $^{54}$ 
a)
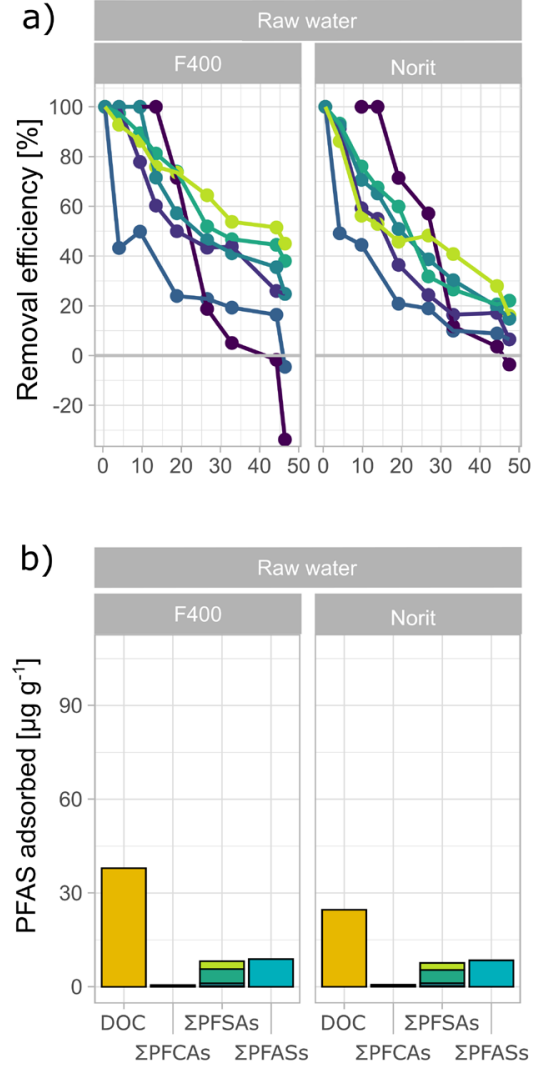

c)

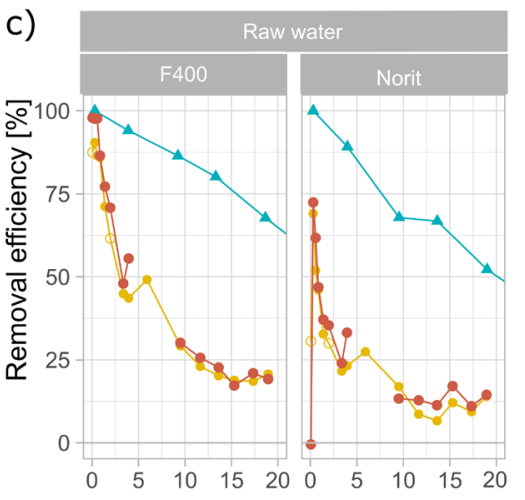

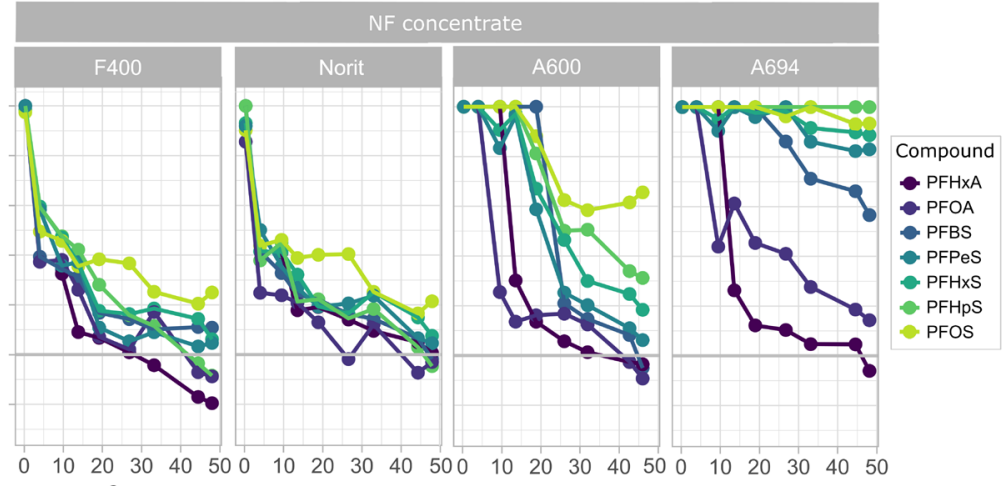

$10^{3}$ treated bed volumes
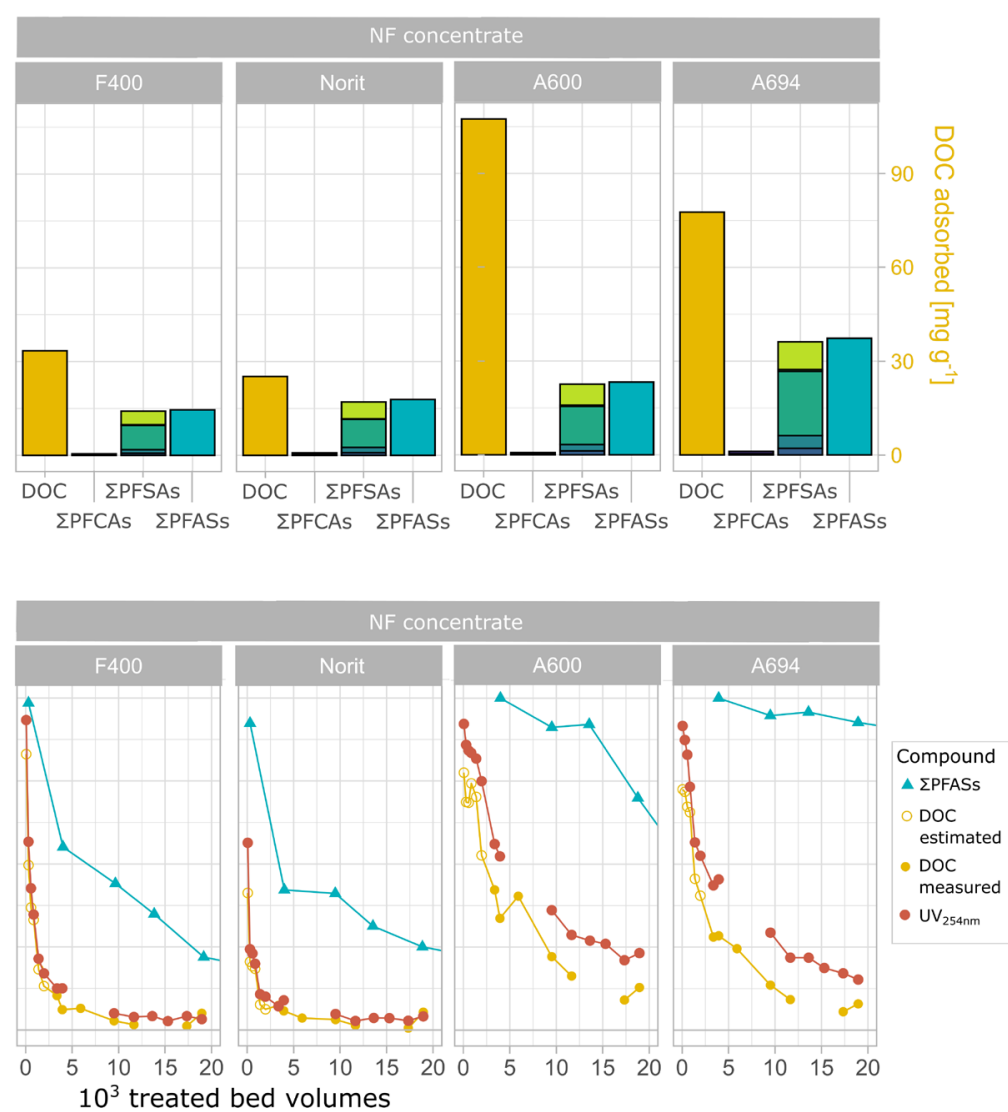

Figure 3. (a) Removal efficiency (\%) of PFASs during the course of the column experiments, (b) total mass loading of PFASs ( $\mu \mathrm{g} \mathrm{g}^{-1}$ of filter material) at the end of the column experiments $\left(48000 \mathrm{BV}_{\text {treated }}\right)$ and $\mathrm{DOC}\left(\mathrm{mg} \mathrm{g}^{-1}\right.$ filter material) after a total of $\left.20000 \mathrm{BV}_{\text {treated }}\right)$, and (c) removal efficiency (\%) of dissolved organic carbon (DOC) and compounds causing UV absorption at $254 \mathrm{~nm}\left(\mathrm{UV}_{254 \mathrm{~nm}}\right)$ for the first 20000 $\mathrm{BV}_{\text {treated }}$. The removal efficiency for the sum of detected PFASs is depicted for reference (blue line with triangular markers); A600, Purolite A600; A694, Purofine PFA694; F400, Filtrasorb 400; Norit, Norit 1240 W; NF, nanofiltration.

It is often hypothesized that background DOC concentrations influence organic micropollutant adsorption negatively in the long term as DOC competes for and blocks or fouls adsorption sites. ${ }^{22,34,55}$ While this is especially true for GAC, the PFAS removal efficiency of AIX resins remains rather unaffected by background DOC, as observed in the current study as well as in earlier studies. ${ }^{28,56}$ Additionally, ${ }^{56}$ DOC was found to assist PFAS absorption on GAC in the preequilibrium stage of GAC loading, suggesting that the dominating PFAS adsorption mechanism changes over time and highlighting the complex influence of the DOC content on PFAS adsorption. Many studies have tried to explain the capacity of adsorption materials for organic micropollutants with regard to various parameters influencing organic micropollutant uptake. ${ }^{55-58}$ Zietzschmann et al. ${ }^{58}$ found that breakthrough curves of organic micropollutants and GAC capacities superimpose each other for different water types when the specific throughput of different DOC fractions of the waters are considered. ${ }^{58}$ In this study, the UV adsorption and DOC content of the whole samples were evaluated. When plotting the relative effluent concentrations $\left(c / c_{0}\right)$ of PFASs against the specific throughput of DOC or the integrated UV absorption at $254 \mathrm{~nm}$, the curves for both water types came close to superimposing each other (Figure 4 and Figure S.7 in the SI). A normalization of $c / c_{0}$ toward the absolute mass of DOC, the absolute amount of UV adsorbed to the column 


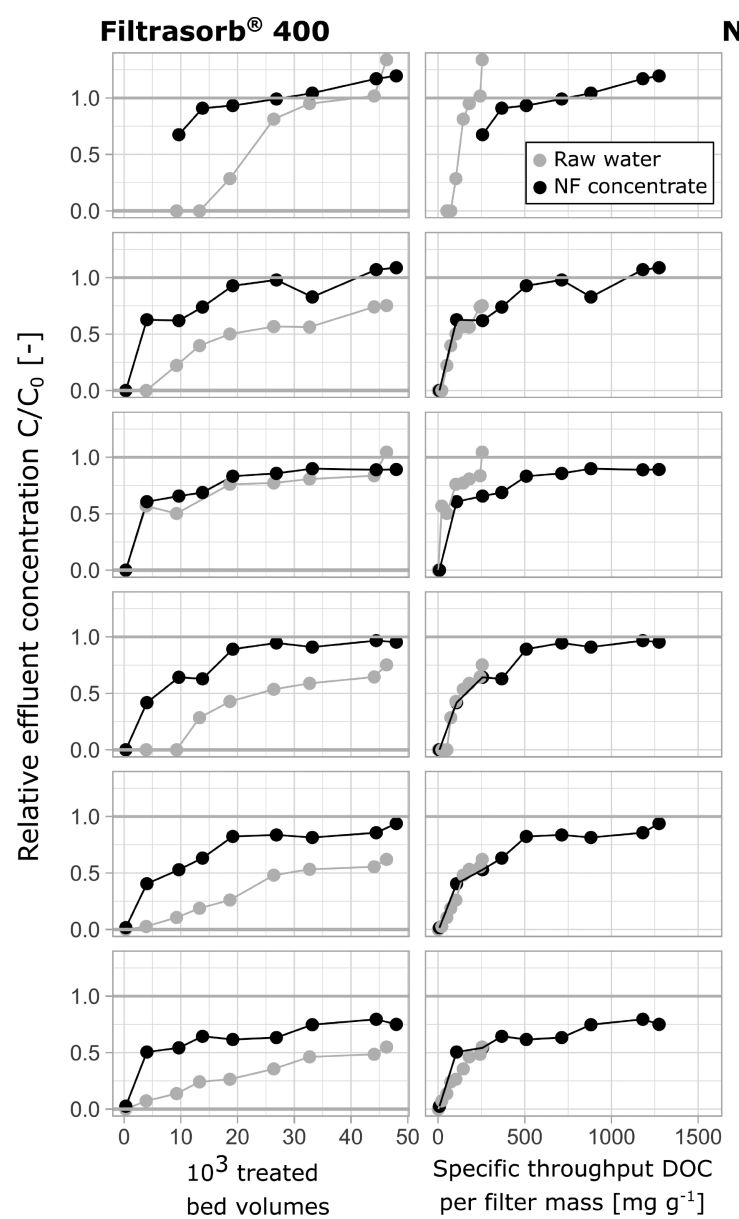

Norit 1240 W

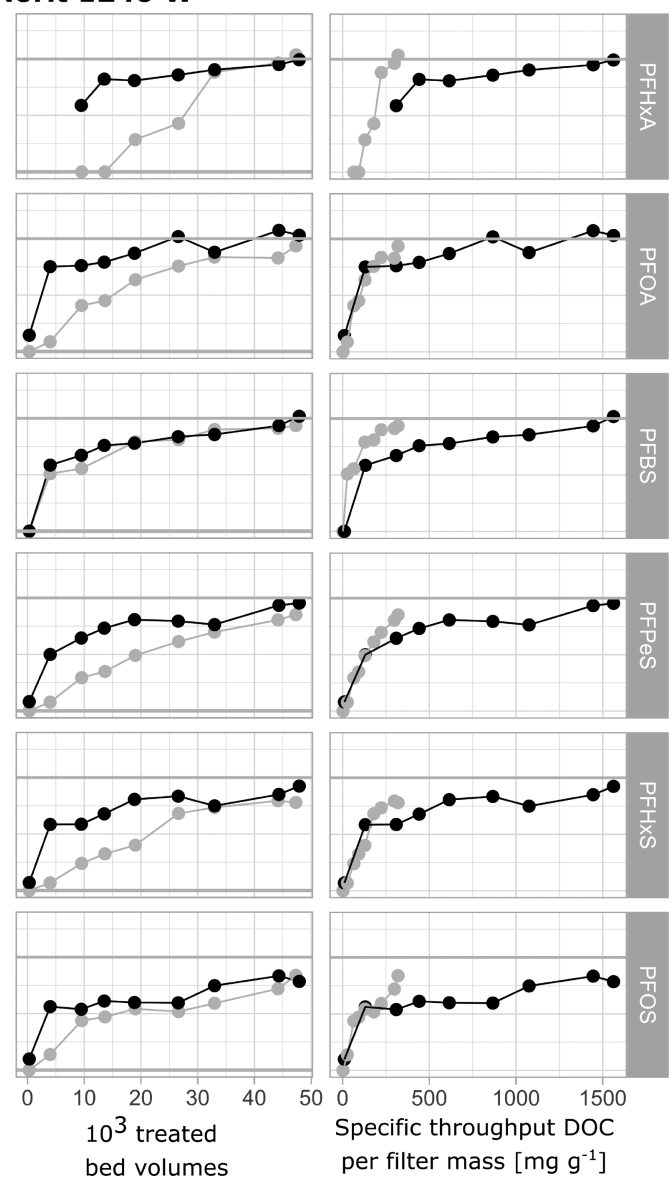

Figure 4. Relative effluent concentrations $\left(c / c_{0}\right)$ of various PFASs detected in both the raw water and the nanofiltration (NF) concentrate for the GAC materials (a) Filtrasorb 400 and (b) Norit $1240 \mathrm{~W}$. Relative concentrations are plotted over the total BV $\mathrm{Breated}_{\text {te }}$ as well as the specific throughput of DOC and UV.

materials, or the difference in ingoing PFAS concentrations did not result in superimposed curves (Figure S.8 in the SI). Thus, normalization toward the specific throughput of the full DOC content, which is defined as the absolute mass of the organic matter that was fed to the adsorption materials (grams of DOC per gram of filter material) as opposed to the absolute mass of carbon adsorbed, ${ }^{58}$ was found to explain the differences in PFAS $c / c_{0}$ for the different water types in this study. As can be seen from the illustration of $c / c_{0}$ with the throughput in $\mathrm{BV}_{\text {treated }}$ (Figure 4), breakthrough occurs earlier for the GAC columns treating the NF concentrate in comparison to the ones treating raw water. This, with the exception for PFBS for which breakthrough curves are very close to each other for both water types for both GAC materials evaluated, could be explained by the fact that small organic molecules compete more effectively for adsorption sites than larger molecules of a similar polarity. ${ }^{57}$ It should be noted that results for the adsorption of organic micropollutants obtained by different studies are often not comparable because experimental parameters, such as column dimension, material type, flowrates, and water quality, differ substantially, and models describing micropollutant breakthrough based on water quality parameters are still scarce. ${ }^{58}$ However, being able to compare PFAS breakthrough for the two different water types evaluated in the manner as shown above provides a useful tool for a large-scale application of the combination of NF with GAC, as recoveries might change during NF operation and the influence of a subsequently changed DOC content on PFAS removal by GAC could therefore be predicted. One example of the current relevance is the new safety threshold for tolerable weekly intakes of several PFASs issued by the European Food Safety Authority, which is likely to impact treatment goals for PFASs in drinking water in European countries. ${ }^{59}$ While it should not replace PFAS measurements, estimations on the GAC lifetime can be valuable planning tools for drinking water providers applying this type of treatment.

3.4. Influence of Solution lonic Strength Using AIX Filters. PFAS removal via ion exchange, the main adsorption mechanism of AIX, was expected to be influenced negatively by the high amount of anions in the NF concentrate. The breakthrough of alkalinity as well as breakthrough sulfate $\left(\mathrm{SO}_{4}^{2-}\right)$, chloride $\left(\mathrm{Cl}^{-}\right)$, and fluoride $\left(\mathrm{F}^{-}\right)$concentrations were therefore monitored for the AIX columns in the beginning of the experiment. As can be seen in Figure S.9 in the SI, the monitored anions $\mathrm{SO}_{4}^{2-}, \mathrm{Cl}^{-}$, and $\mathrm{F}^{-}$reached complete breakthrough (ingoing concentrations $\approx$ outgoing concentrations) at $<300 \mathrm{BV}_{\text {treated }}$. Total loadings on the resins were estimated to be 64 (Purolite A600) and $66 \mathrm{mg} \mathrm{g}^{-1}$ (Purofine PFA694) for $\mathrm{SO}_{4}^{2-}$ and 0.12 (Purolite A600) and $0.12 \mathrm{mg} \mathrm{g}^{-1}$ (Purofine PFA694) for $\mathrm{F}^{-}$. Outgoing $\mathrm{Cl}^{-}$concentrations decreased during $0-300 \mathrm{BV}_{\text {treated }}$ which was expected as the resins are delivered in the $\mathrm{Cl}^{-}$form. Outgoing $\mathrm{SO}_{4}^{2-}$ concentrations increased during $0-300 \mathrm{BV}_{\text {treated }}$ and remained stable thereafter, while the breakthrough of $\mathrm{F}^{-}$was not 
a)

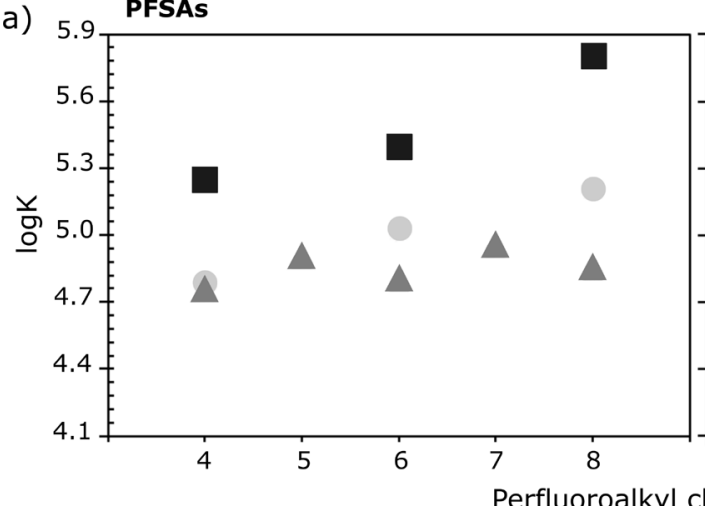

PFCAs

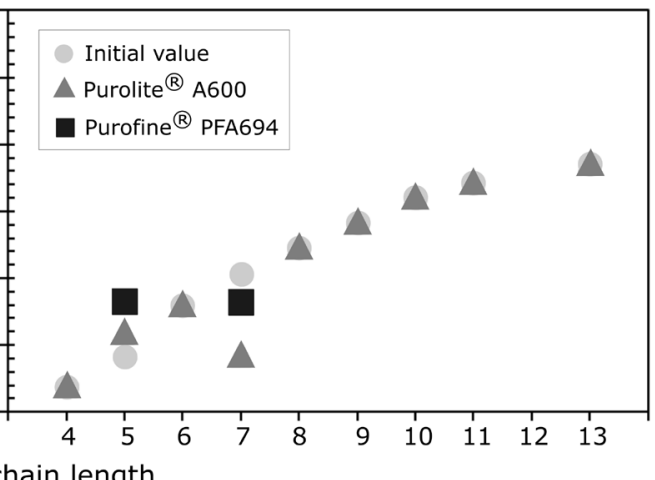

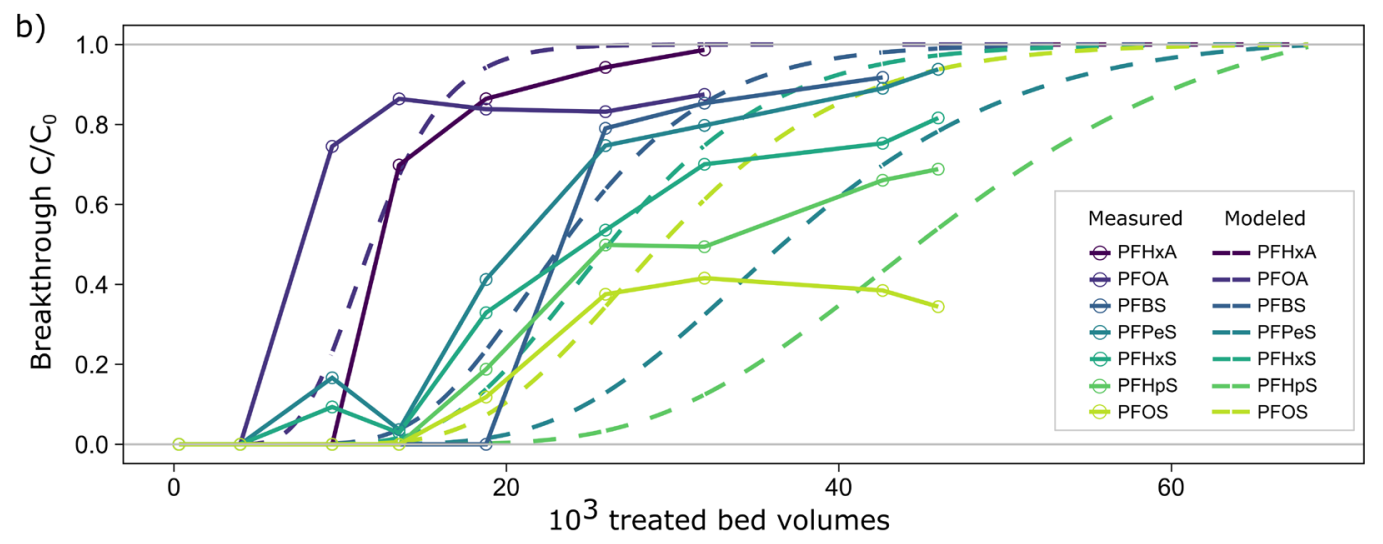

c)

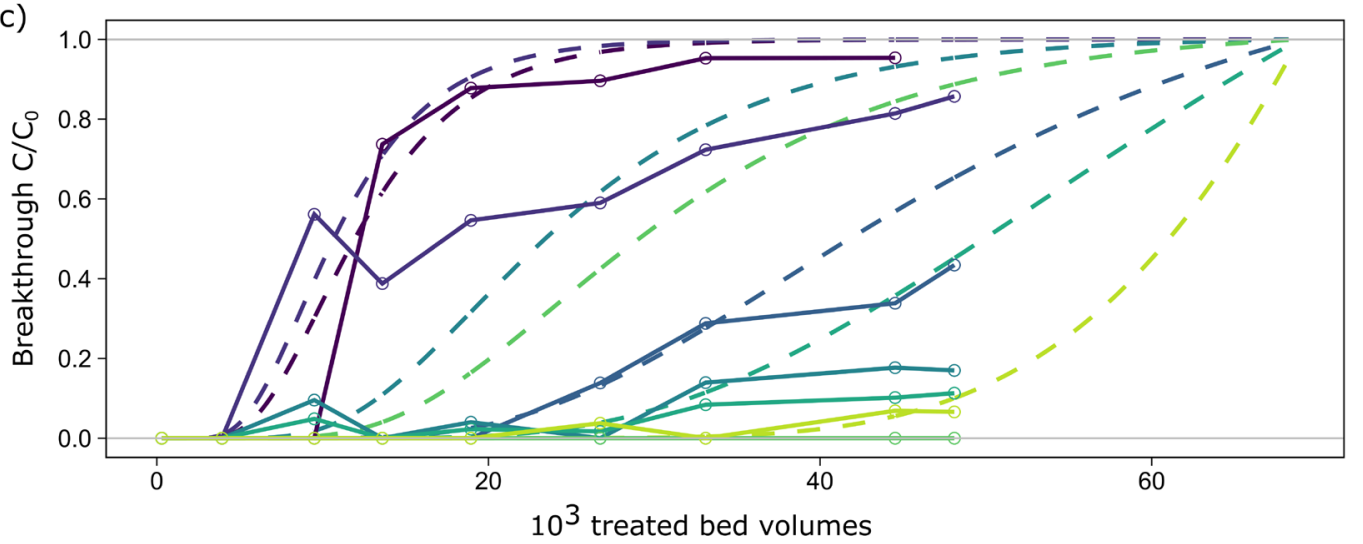

Figure 5. (a) Binding constants $\log K$ used to model the binding of PFAS substances as a function of the perfluororoalkyl chain length of PFSAs and PFCAs. Intitial values refer to the values derived in ref 35. (b) Relative breakthrough $c / c_{0}$ as a function of $B V_{\text {treated }}$ for the Purolite $A 600$ and (c) Purofine PFA694 resin material.

captured by the grab samples and therefore occurred faster than that at $24 \mathrm{BV}_{\text {treated }}$ (Figure S.9 in the SI). Measurements of alkalinity (as $\mathrm{CaCO}_{3}$ ) suggest a slower breakthrough of alkalinity than for breakthroughs for $\mathrm{SO}_{4}^{2-}, \mathrm{Cl}^{-}$, and $\mathrm{F}^{-}$. Outgoing concentrations of $\sum$ PFASs in the AIX columns larger than the LOQ were not observed until $>5000 \mathrm{BV}_{\text {treated }}$ (Figure 3c). A systematic examination of the influence of the ionic strength on PFAS adsorption was outside the scope of this study. Nevertheless, the obtained results highlight that dominant anionic species reached breakthrough much faster than PFASs for the AIX materials treating the NF concentrate. PFAS adsorption appears to occur independently of the adsorption of the major anions despite the greater anion concentration in the concentrate. Gao et al. ${ }^{60}$ explored the adsorption of PFOS and its replacement compound F-53B onto a similar AIX resin (IRA67) as the ones applied in the current study. They concluded that at an ambient $\mathrm{pH}$ of $\approx 7$ electrostatic interactions (i.e., anion exchange) dominated the adsorption mechanisms of the PFASs as well as that other mechanisms, such as hydrophobic interactions and micelle formation, played a significant role in adsorption. ${ }^{60}$ When studying PFCA adsorption on the IRA67 resin, Du et al. ${ }^{61}$ found that the effect of inorganic salts generally had a minor effect on the evaluated PFCA (PFHxA, PFHpA, and PFOA) adsorption to IRA67 with the exception of $\mathrm{SO}_{4}^{2-}\left(0.6 \mathrm{mmol}^{-1}\right.$ $=59 \mathrm{mg} \mathrm{L}^{-1}$ ), which slightly lowered the total PFCA removal by IRA67. It is worth noting that initial PFAS concentrations in the studies by $\mathrm{Gao}^{60}$ and $\mathrm{Du}^{61}$ were much higher (milligram per liter ranges) compared to our study, and the authors considered batch adsorption experiments; meanwhile, the observations of the current study are based on flow-through experiments. Thus, this flow-through experiment could 

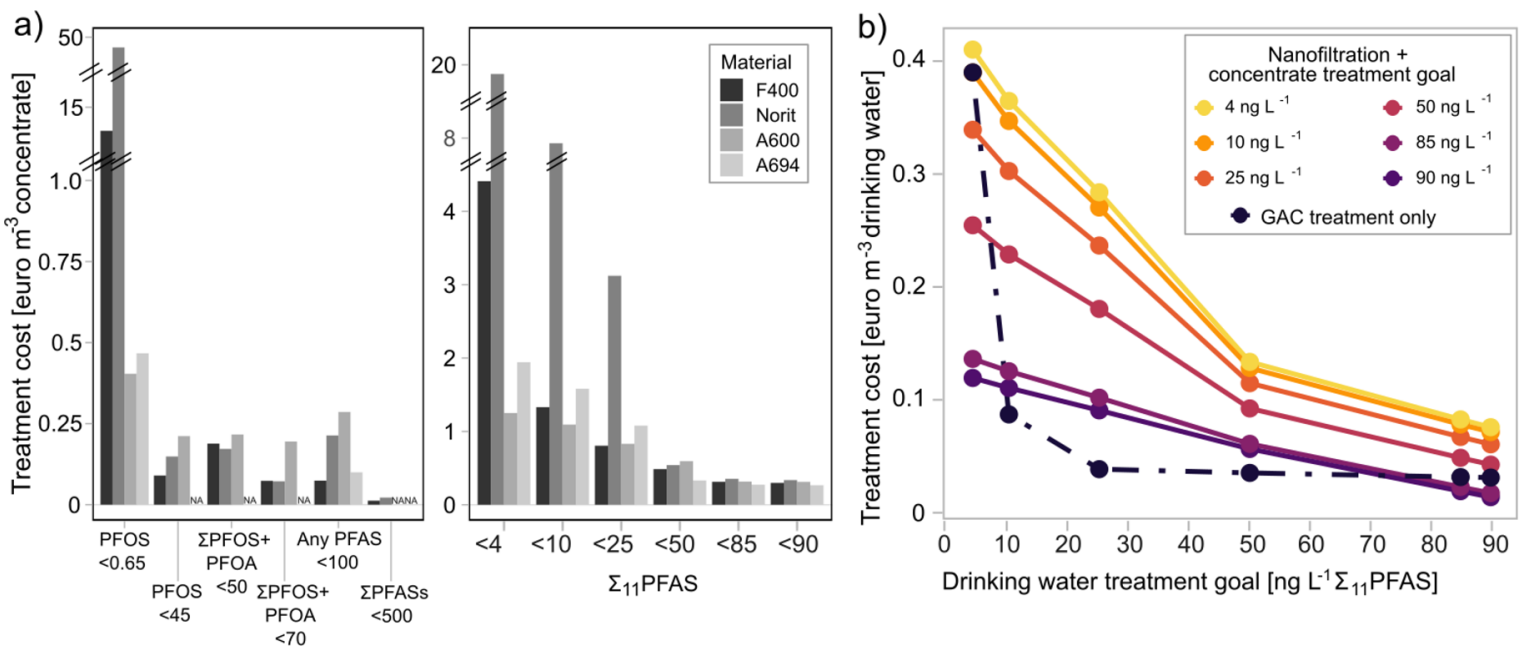

Figure 6. (a) Annual operation costs (euro $\mathrm{m}^{-3}$ treated concentrate) arising from the treatment of the nanofiltration concentrate to various concentrate discharge goals $\left(\mathrm{ng} \mathrm{L}^{-1}\right)$. Goals on the left panel include guidelines for surface, ground, and drinking water issued by various national and international agencies (for more details see Table S.13 in the SI). Goals on the right panel are in regard to the sum of 11 PFASs included in the Swedish drinking water guidelines. ${ }^{43}$ NA, not available; the specific discharge goal was not reached for the material and thus costs could not be derived. (b) Operation cost comparison for the reduction of $\sum_{11}$ PFAS concentrations to various discharge goals using nanofiltration for drinking water production and an AIX treatment for the resulting concentrate treatment. The GAC treatment for various drinking water treatment goals is included for comparison. The analysis assumed conditions given at Bäcklösa DWTP with a production of 7 million $\mathrm{m}^{3}$ of drinking water per year.

potentially underestimate equilibrium conditions since the contact time is on the order of minutes, while much larger contact times are employed in batch experiments (up to days). This study focused on the practical application with a defined flow and thus contact time, which is important for the evaluation of full-scale systems.

3.5. Modeling PFAS Breakthrough Using the PHREEQC Model. The fitted binding constants $\log K$ revealed a linear increase for increasing perfluoroalkyl chain lengths (Figure 5a). The difference in $\log K$ values between PFSAs and PFCAs was observed to be smaller for perfluoroalkyl carbon chains and approached zero for a chain length of nine (Figure S.10 in the SI). This observation is in accordance with a more dominant hydrophobic binding effect as the chain length increases. Breakthrough curves of most PFASs observed in the current study were less distinct than those observed by Zaggia et $\mathrm{al}^{27}$ (Figure $5 \mathrm{~b}$ and $\mathrm{c}$ ). The need to change the dispersion constant in the Purofine PFA694 experiment from the initial values of the Purolite A600 material to much higher values suggests either a significant effect of the DOC accumulation on the Purofine PFA694 material or another significant nonstatic binding mechanism developing over time. Future research should focus on the effect of different flow rates and different organic matter contents on PFAS breakthrough. Simulated changes in the anion exchange capacity (AEC) and the binding constant $\log K$ produced expected changes in breakthrough behavior, i.e., a proportional prolongation of the treatment performance was observed with an increasing AEC and rising $\log K$ values (Figure S.11 in the SI). While changes in the AEC mostly led to a delayed breakthrough with a negligible impact on the shape of the breakthrough curves, changes in $\log K$ values produced a much flatter breakthrough curve. Stronger binding, as expressed in larger $\log K$ values, therefore leads to longer retention times, thus increasing dispersion effects. In practice, breakthrough can be expected to be less distinct and lead to criteria for deciding when to replace the AIX that are more complex. Breakthrough in the current Purolite A600 column experiments revealed a much smaller difference in the timing of breakthrough of PFBS and PFOA than what was observed by Zaggi et al. ${ }^{27}$ PFBS and PFOA entering a column filled with Purolite A600 at similarly high inlet concentrations (ca. 200-400 ng L ${ }^{-1}$ ) experienced breakthrough after 10000 $\mathrm{BV}_{\text {treated }}$ (PFBS) and $48000 \mathrm{BV}_{\text {treated }}$ (PFOA), respectively. ${ }^{27}$ The observed complete breakthrough occurred at 12000 $\mathrm{BV}_{\text {treated }}$ for PFBS $\left(33 \mathrm{ng} \mathrm{L}^{-1}\right)$ and already occurred at around $24000 \mathrm{BV}_{\text {treated }}$ for PFOA $\left(20 \mathrm{ng} \mathrm{L}^{-1}\right)$ in the current study (Figure $3 \mathrm{a}$ ). Based on the current data, we cannot exclude that there is a competing effect of organic matter in our system. To model that effect on a quantitative basis, however, experiments at different organic matter concentrations would be necessary. Another reason is the much higher relative concentration of strongly binding PFOS in the inlet during the current experiments (130 $\left.\mathrm{ng} \mathrm{L} \mathrm{L}^{-1}\right)$. PFOS is expected to occupy binding sites and compete with all weaker binding substances. Breakthrough of weaker binding PFASs is therefore likely to occur earlier with higher relative concentrations of strongly binding PFASs is in the raw water. This emphasizes the need for a reliable modeling tool when treating a complex mixture of competing substances with different concentrations. Even if the model's simple chemical representation of pure ion exchange is not in complete accordance with the frequently observed hydrophobic interactions and micelle formation, it is valuable for making realistic estimates or breakthrough patterns that are relevant for treatment management decisions.

3.6. Economic Considerations for the Combination of Nanofiltration with Adsorption Materials. The comparative annual operations costs for GAC or AIX treatment of the PFAS-laden NF concentrate for a range of discharge goals are illustrated in Figure 6a. The results for annual operations unit costs for the NF concentrate management with regard to the different concentrate discharge goals show that for Bäcklösa DWTP it would be cost-effective to apply AIX resins for most discharge goals from 4 to $90 \mathrm{ng} \mathrm{L}^{-1}$ (Purofine PFA694 for PFAS concentrate discharge goals of $90-50 \mathrm{ng} \mathrm{L}^{-1}$ and Purolite A600 for 25-4 ng L ${ }^{-1}$ ), while Filtrasorb 400 would only be economically competitive at the discharge goal of 
$\sum_{11}$ PFAS $<25 \mathrm{ng} \mathrm{L}^{-1}$ (Figure 6a and Table S.13 in the SI). These results reflect the performance characteristics of GAC and AIX resins used in the experiment when treating the PFAS-laden NF concentrate (also see Table S.13 in the SI). Due to the outstanding capacity of the AIX resins for PFOS, any of the evaluated AIX resins would be considerably less operations cost intensive for NF concentrate treatment for discharge goals focusing only on the release of PFOS compared to the evaluated GAC materials.

Figure $6 \mathrm{~b}$ shows the annual unit costs for NF treatment combined with the AIX for treatment of the resulting concentrate to drinking water and discharge goals ranging from 90 to $4 \mathrm{ng} \mathrm{L}^{-1} \sum_{11}$ PFAS for an annual production of 7 million $\mathrm{m}^{3}$ of drinking water at the Bäcklösa DWTP. Also shown in Figure $6 \mathrm{~b}$ is the operations cost for single-pass GAC treatment to achieve the same water treatment goals. It appears that for Bäcklösa DWTP the operational cost for NF combined with AIX for concentrate treatment is chiefly a function of the concentrate discharge goal and not the drinking water treatment goal for drinking water treatment goals from 90 to $50 \mathrm{ng} \mathrm{L}^{-1}$, whereas the cost is a function of both drinking water and concentrate discharge goals for drinking water treatment goals less than $50 \mathrm{ng} \mathrm{L^{-1 }}$. NF combined with the AIX treatment was determined to result in a similar costs as that for using GAC when a drinking water goal is $4 \mathrm{ng} \mathrm{L}^{-1} \sum_{11}$ PFAS and the treated concentrate goal is $10 \mathrm{ng} \mathrm{L^{-1 }}$ or less. At drinking water treatment goals from approximately 10 to $75 \mathrm{ng}$ $\mathrm{L}^{-1}$, GAC provides a more cost-efficient drinking water treatment, including PFAS destruction. Interestingly, costs for NF combined with the AIX treatment of the NF concentrate were found to be comparable or lower than those for GAC treatment if the drinking water quality goal is greater than $75 \mathrm{ng} \mathrm{L}^{-1} \sum_{11}$ PFAS and discharge goals are higher than $85 \mathrm{ng} \mathrm{L}^{-1} \sum_{11}$ PFAS.

It is important to highlight the economic value, aside from separating PFAS from the feedwater, that NF provides through the removal of additional substances in the raw water, such as hardness, DOC, uranium, etc., as illustrated at the Bäcklösa site as shown in Figure 2 and Table S.1 in the SI. This value was not included in the present study's economic analysis. Similarly, the use of regenerable resins for PFAS removal would increase the economic viability of AIX, and future work in this area is needed. ${ }^{27,62}$ Note that the majority of discharge goals chosen for the cost calculations and presented in Figure $6 \mathrm{a}$ are based on guidelines for drinking water. General guidelines for maximum PFAS concentrations for surface water are scarce. When considering the Environmental Quality Standard included in the EU Water Framework Directive with respect to the findings of this study, it remains debatable if PFOS should be the only PFAS considered when choosing discharge goals for the NF concentrate. Even when considering the release of the sum of the 11 PFASs included in the current Swedish drinking water guidelines, several other PFASs might be released into the environment at considerable concentrations (e.g., PFPeS). In line with the currently discussed grouping approach, ECHA further proposed a $0.5 \mu \mathrm{g} \mathrm{L}^{-1}$ limit for all PFASs in final drinking water as part of the European Drinking Water Directive. ${ }^{63,64}$ It goes without saying that any release of PFASs to the environment is undesirable not only because surface waters serve as drinking water sources and conventional drinking water treatment is incapable of satisfactory PFAS removal. ${ }^{17,23}$ It is recognized that this demand might not be enforceable for drinking water providers, and streamlined guidelines for the release of PFASs into the environment should be put in place for guidance.

\section{CONCLUSIONS}

In this study, we confirmed the suitability of NF for the efficient removal of PFASs from an impacted groundwater source used for drinking water production. NF was also shown to successfully remove uranium-238, DOC, bromide, and mineral hardness. Using AIX resins for the removal of PFASs from the NF concentrate was shown to be more efficient than the use of GAC based on the total amount of bed volumes the materials could treat before reaching a range of discharge goals. In a comparison of GAC materials treating both raw water and the NF concentrate, it was shown that, with the exception of PFBS, differences in the PFAS breakthrough could be explained by the specific breakthrough of DOC. The application of the freely available PHREEQC model revealed that larger dispersion effects can be expected for resins with larger binding constants. An increase in the anion exchange capacity would most likely delay the PFAS breakthrough proportionally. An investigation of the relative operations costs of each evaluated adsorbent material for various concentrate discharge goals showed that the application of AIX resins to reach discharge goals of $\sum$ PFAS $4-90 \mathrm{ng} \mathrm{L}^{-1}$ would be more cost-effective than using GAC for the concentrate treatment. Additionally, using AIX resins instead of GAC was shown to result in much lower unit costs for discharge goals focusing on PFOS. When considering drinking water treatment, GAC provides a more cost-efficient removal of PFAS, including PFAS destruction, than NF at drinking water treatment goals from approximately 10 to $75 \mathrm{ng} \mathrm{L}{ }^{-1} \sum_{11}$ PFAS. For drinking water treatment goals greater than $75 \mathrm{ng} \mathrm{L}^{-1}$, NF with a concentrate treatment is cost-effective if the NF's concentrate discharge goal is less that $85 \mathrm{ng} \mathrm{L}^{-1} \sum_{11}$ PFAS. This illustrates the impact and economic importance of discharge goals when selecting between GAC or NF for PFAS reduction if regulatory limitations are considered for the discharge of the membrane concentrate.

On a general note, the authors consider the use of treatment processes primarily based on size exclusion, such as nanofiltration, to be the most promising chemical barriers in drinking water production available today. The amount of produced and emitted man-made chemicals in the environment is only expected to increase, and pressure on drinking water sources will have to be taken into consideration. As analytical methods are developed rapidly, regulations for drinking water quality can be expected to become stricter, and drinking water treatment needs to be fit for the removal of various chemical hazards. New and emerging contaminants with various physicochemical properties are detected in the aquatic environment on a regular basis, which is also the case for PFASs. For the production of safe and clean water with minimal PFAS concentrations, treatment processes based on size exclusion can be expected to outcompete adsorption processes, which often target contaminants with specific properties. However, the drawback of the resulting concentrate water needs further attention, and as shown in this study filtration through suitable adsorption materials such as AIX resins can be an advisible management technique. Future research should evaluate the possibility of regenerating spent AIX resins on-site as well as determine the most economic concentrate treatment option or examine PFAS destructive 
methods that are compatible with characteristics of the NF concentrate stream, i.e., electrochemical processes.

\section{ASSOCIATED CONTENT}

\section{SI Supporting Information}

The Supporting Information is available free of charge at https://pubs.acs.org/doi/10.1021/acsestwater.0c00141.

Additional data for the nanofiltration process, details on the chemical analysis, additional information on the PHREEQC model, additional data for the economic analysis, and additional graphs and data referred to in the manuscript (PDF)

\section{AUTHOR INFORMATION}

\section{Corresponding Authors}

Vera Franke - Swedish University of Agricultural Sciences,

Department of Aquatic Sciences and Assessment, 75007

Uppsala, Sweden; 이이이.org/0000-0001-5390-8547;

Email: vera.franke@slu.se

Malin Ullberg - Swedish University of Agricultural Sciences, Department of Aquatic Sciences and Assessment, 75007

Uppsala, Sweden; Email: malin.ullberg@slu.se

\section{Authors}

Philip McCleaf - Uppsala Water and Waste AB, 75144 Uppsala, Sweden

Maria Wålinder - Swedish University of Agricultural Sciences, Department of Aquatic Sciences and Assessment, 75007 Uppsala, Sweden

Stephan J. Köhler - Swedish University of Agricultural Sciences, Department of Aquatic Sciences and Assessment, 75007 Uppsala, Sweden

Lutz Ahrens - Swedish University of Agricultural Sciences,

Department of Aquatic Sciences and Assessment, 75007

Uppsala, Sweden; 이이이.org/0000-0002-5430-6764

Complete contact information is available at:

https://pubs.acs.org/10.1021/acsestwater.0c00141

\section{Notes}

The authors declare no competing financial interest.

\section{ACKNOWLEDGMENTS}

This work was partly funded by the Swedish Research Council Formas (PFAS-FREE, contract no. 942-2015-1554 and contract no. 201600681) as well as by Swedish Water (DRICKS; SVU 20-121) and by Uppsala Water and Waste $A B$. We would like to thank Uppsala Water and Waste $A B$, especially the employees working at Bäcklösa, for the for valuable support. We thank Johannes Kikuchi for all the crucial help in the laboratory. The data collected during this study are available upon request from the authors.

\section{REFERENCES}

(1) Organisation for Economic Co-operation and Development. Toward a New Comprehensive Global Database of Per- And Polyfluoroalkyl Substances (PFASs): Summary Report on Updating the OECD 2007 List of Per- And Polyfluoroalkyl Substances (PFASs); OECD: Paris, France, 2018; p 39. https://www.oecd.org/ officialdocuments / publicdisplaydocumentpdf/? cote=ENV-JMMONO(2018) $7=$ en.

(2) Buck, R. C.; Franklin, J.; Berger, U.; Conder, J. M.; Cousins, I. T.; de Voogt, P.; Jensen, A. A.; Kannan, K.; Mabury, S. A.; van Leeuwen, S. P. Perfluoroalkyl and polyfluoroalkyl substances in the environment: Terminology, classification, and origins. Integr. Environ. Assess. Manage. 2011, 7 (4), 513-541.

(3) Interstate Technology \& Regulatory Council. PFAS Technical and Regulatory Guidance Document and Fact Sheets; ITRC: Washington, D.C., 2020. https://pfas-1.itrcweb.org/.

(4) Ahrens, L. Polyfluoroalkyl compounds in the aquatic environment: a review of their occurrence and fate. J. Environ. Monit. 2011, 13 (1), 20-31.

(5) Ahrens, L.; Bundschuh, M. Fate and effects of poly- and perfluoroalkyl substances in the aquatic environment: A review. Environ. Toxicol. Chem. 2014, 33 (9), 1921-1929.

(6) European Chemicals Agency. Candidate List of substances of very high concern for Authorisation; ECA: Helsinki, Finland,https://echa. europa.eu/candidate-list-table (accessed 2020-07-09).

(7) Kissa, E. Fluorinated Surfactants and Repellents; Marcel Dekker, Inc.: New York, NY, 2001.

(8) Goldenman, G.; Fernandes, M.; Holland, M.; Tugran, T.. The cost of inaction: A socioeconomic analysis of environmental and health impacts linked to exposure to PFAS; TemaNord; Nordisk Ministerråd: Copenhagen, Denmark, 2019; p 516.

(9) Cousins, I. T.; Goldenman, G.; Herzke, D.; Lohmann, R.; Miller, M.; Ng, C. A.; Patton, S.; Scheringer, M.; Trier, X.; Vierke, L.; Wang, Z.; DeWitt, J. C. The concept of essential use for determining when uses of PFASs can be phased out. Environ. Sci.: Processes Impacts 2019, $21,1803-1815$.

(10) Gyllenhammar, I.; Benskin, J. P.; Sandblom, O.; Berger, U.; Ahrens, L.; Lignell, S.; Wiberg, K.; Glynn, A. Perfluoroalkyl acids (pfaas) in children's serum and contribution from pfaa-contaminated drinking water. Environ. Sci. Technol. 2019, 53 (19), 11447-11457.

(11) Moody, C. A.; Hebert, G. N.; Strauss, S. H.; Field, J. A. Occurrence and Persistence of Perfluorooctanesulfonate and Other Perfluorinated Surfactants in Groundwater at a Fire-Training Area at Wurtsmith Air Force Base, Michigan, USA. J. Environ. Monit. 2003, 5 (2), 341-345.

(12) Schultz, M. M.; Higgins, C. P.; Huset, C. A.; Luthy, R. G.; Barofsky, D. F.; Field, J. A. Fluorochemical mass flows in a municipal wastewater treatment facility. Environ. Sci. Technol. 2006, 40 (23), $7350-7357$.

(13) Vestergren, R.; Cousins, I. T. Tracking the pathways of human exposure to perfluorocarboxylates. Environ. Sci. Technol. 2009, 43 (15), 5565-5575.

(14) Thompson, J.; Eaglesham, G.; Reungoat, J.; Poussade, Y.; Bartkow, M.; Lawrence, M.; Mueller, J. F. Removal of PFOS, PFOA and other perfluoroalkyl acids at water reclamation plants in South East Queensland, Australia. Chemosphere 2011, 82 (1), 9-17.

(15) Eschauzier, C.; Beerendonk, E.; Scholte-Veenendaal, P.; De Voogt, P. Impact of treatment processes on the removal of perfluoroalkyl acids from the drinking water production chain. Environ. Sci. Technol. 2012, 46 (3), 1708-1715.

(16) Appleman, T. D.; Higgins, C. P.; Quinones, O.; Vanderford, B. J.; Kolstad, C.; Zeigler-Holady, J. C.; Dickenson, E. R.V. Treatment of poly- and perfluoroalkyl substances in U.S. full-scale water treatment systems. Water Res. 2014, 51, 246-255.

(17) Rahman, M. F.; Peldszus, S.; Anderson, W. B. Behaviour and fate of perfluoroalkyl and polyfluoroalkyl substances (PFASs) in drinking water treatment: A review. Water Res. 2014, 50, 318-340.

(18) Rumsby, P. C.; McLaughlin, C. L.; Hall, T. Perfluorooctane sulphonate and perfluorooctanoic acid in drinking and environmental waters. Philos. Trans. R. Soc., A 2009, 367 (1904), 4119-4136.

(19) Ochoa-Herrera, V.; Sierra-Alvarez, R. Removal of perfluorinated surfactants by sorption onto granular activated carbon, zeolite and sludge. Chemosphere 2008, 72 (10), 1588-1593.

(20) Senevirathna, S. T. M. L. D.; Tanaka, S.; Fujii, S.; Kunacheva, C.; Harada, H.; Shivakoti, B. R.; Okamoto, R. A comparative study of adsorption of perfluorooctane sulfonate (PFOS) onto granular activated carbon, ion-exchange polymers and non-ion-exchange polymers. Chemosphere 2010, 80 (6), 647-651. 
(21) Hansen, M. C.; Børresen, M. H.; Schlabach, M.; Cornelissen, G. Sorption of perfluorinated compounds from contaminated water to activated carbon. J. Soils Sediments 2010, 10, 179-185.

(22) McCleaf, P.; Englund, S.; Östlund, A.; Lindegren, K.; Wiberg, K.; Ahrens, L. Removal efficiency of multiple poly- and perfluoroalkyl substances (PFASs) in drinking water using granular activated carbon (GAC) and anion exchange (AE) column tests. Water Res. 2017, 120, 77-87.

(23) Belkouteb, N.; Franke, V.; McCleaf, P.; Kohler, S.; Ahrens, L. Removal of per- and polyfluoroalkyl substances (PFASs) in a full-scale drinking water treatment plant: long-term performance of granular activated carbon (GAC) and influence of flow-rate. Water Res. 2020, $182,115913$.

(24) Yu, Q.; Zhang, R.; Deng, S.; Huang, J.; Yu, G. Sorption of perfluorooctane sulfonate and perfluorooctanoate on activated carbons and resin: Kinetic and isotherm study. Water Res. 2009, 43 (4), 1150-1158.

(25) Dudley, Leigh-Ann. Removal of Perfluorinated Compounds by Powdered Activated Carbon, Superfine Powder Activated Carbon, and Anion Exchange Resin. Master Thesis, North Carolina State University, Raleigh, NC, 2012.

(26) Du, Z.; Deng, S.; Bei, Y.; Huang, Q.; Wang, B.; Huang, J.; Yu, G. Adsorption behavior and mechanism of perfluorinated compounds on various adsorbents-A review. J. Hazard. Mater. 2014, 274, 443454.

(27) Zaggia, A.; Conte, L.; Falletti, L.; Fant, M.; Chiorboli, A. Use of strong anion exchange resins for the removal of perfluoroalkylated substances from contaminated drinking water in batch and continuous pilot plants. Water Res. 2016, 91, 137-146.

(28) Franke, V.; McCleaf, P.; Lindegren, K.; Ahrens, L. Efficient removal of per- and polyfluoroalkyl substances (PFASs) in drinking water treatment: nanofiltration combined with active carbon or anion exchange. Environ. Sci.: Water Res. Technol. 2019, 5, 1836-1843.

(29) Van der Bruggen, B.; Lejon, L.; Vandecasteele, C. Reuse, treatment, and discharge of the concentrate of pressure-driven membrane processes. Environ. Sci. Technol. 2003, 37 (17), 37333738

(30) Crone, B. C.; Speth, T. F.; Wahman, D. G.; Smith, S. J.; Abulikemu, G.; Kleiner, E. J.; Pressman, J. G. Occurrence of per- and polyfluoroalkyl substances (PFAS) in source water and their treatment in drinking water. Crit. Rev. Environ. Sci. Technol. 2019, 49 (24), 2359-2396.

(31) Singh, R.; Bhadouria, R.; Singh, P.; Kumar, A.; Pandey, S.; Singh, V. K. Nanofiltration technology for removal of pathogens present in drinking water. Waterborne Pathogens 2020, 463-489.

(32) Steinle-Darling, E.; Reinhard, M. Nanofiltration for trace organic contaminant removal: structure, solution, and membrane fouling effects on the rejection of perfluorochemicals. Environ. Sci. Technol. 2008, 42 (14), 5292-5297.

(33) Quiñones, O.; Snyder, S. A. Occurrence of perfluoroalkyl carboxylates and sulfonates in drinking water utilities and related waters from the United States. Environ. Sci. Technol. 2009, 43 (24), 9089-9095.

(34) Appleman, T. D.; Dickenson, E. R.V.; Bellona, C.; Higgins, C. P. Nanofiltration and granular activated carbon treatment of perfluoroalkyl acids. J. Hazard. Mater. 2013, 260, 740-746.

(35) Wålinder, Maria. Modeling of Perfluoroalkyl Substance Adsorption to an Ion Exchanger using PHREEQC. Bachelor Thesis, Swedish University of Agricultural Sciences, Uppsala, Sweden, 2016.

(36) Purolite. Purolite ${ }^{\circledR}$ A600 Product Data Sheet. 2020. https:// www.purolite.com/product-pdf/A600.pdf.

(37) Purolite. Purofine ${ }^{\circledR}$ PFA694E - Product Data Sheet. 2020. https://www.purolite.com/product-pdf/PFA694.pdf.

(38) Szerzyna, S.; Mołczan, M.; Wolska, M.łg.; Adamski, W.; Wisniewski, J. Absorbance based water quality indicators as parameters for treatment process control with respect to organic substance removal. Absorbance based water quality indicators as parameters for treatment process control with respect to organic substance removal 2017, 17 (04), 00091.
(39) Albrektienè, R.; Rimeika, M.; Zalieckienè, E.; Šaulys, V.; Zagorskis, A. Determination of organic matter by uv absorption in the ground water. J. Environ. Eng. Landsc. 2012, 20 (2), 163-167.

(40) ALS Scandinavia. https://www.alsglobal.se/en/searchanalysis?q/pfas (accessed 2019).

(41) OV-34a Perfluorinated Compounds in Water. ALS Scandinavia, 2019.

(42) Ahrens, L.; Taniyasu, S.; Yeung, L. W.Y.; Yamashita, N.; Lam, P. K.S.; Ebinghaus, R. Distribution of polyfluoroalkyl compounds in water, suspended particulate matter and sediment from tokyo bay, japan. Chemosphere 2010, 79 (3), 266-272.

(43) Ankarberg, E. H.; Lindberg, T. Riskhanteringsrapport: Risker vid fororening av dricksvatten med PFAS. Technical report, Swedish National Food Agency: Uppsala, Sweden, 2016.

(44) PHREEQC, ver. 3; U.S. Geological Survey: Denver, CO, 2020. https://www.usgs.gov/software/phreeqc-version-3.

(45) Parkhurst, David L.. User's Guide to PHREEQC: A Computer Program for Speciation, Reaction-Path, Advective-Transport, and Inverse Geochemical Calculations; U.S. Geological Survey: Denver, CO, 1996. https://pubs.usgs.gov/wri/1995/4227/report.pdf.

(46) Appelo, C. A. J.; Parkhurst, D. L.. Calculating Cation Exchange with PHREEQC (Version 2). Dr C.A.J. Appelo -- HYDROCHEMICAL CONSULTANT2002. https://www.hydrochemistry.eu/pub/ap_ pa02.pdf.

(47) Gaines, G. L.; Thomas, H. C. Adsorption studies on clay minerals. ii. a formulation of the thermodynamics of exchange adsorption. J. Chem. Phys. 1953, 21 (4), 714-718.

(48) Tang, C. Y.; Fu, Q. S.; Criddle, C. S.; Leckie, J. O. Effect of flux (transmembrane pressure) and membrane properties on fouling and rejection of reverse osmosis and nanofiltration membranes treating perfluorooctane sulfonate containing wastewater. Environ. Sci. Technol. 2007, 41 (6), 2008-2014.

(49) Boo, C.; Wang, Y.; Zucker, I.; Choo, Y.; Osuji, C. O.; Elimelech, M. High performance nanofiltration membrane for effective removal of perfluoroalkyl substances at high water recovery. Environ. Sci. Technol. 2018, 52, 7279-7288.

(50) Bellona, C.; Drewes, J. E.; Xu, P.; Amy, G. Factors affecting the rejection of organic solutes during NF/RO treatment-a literature review. Water Res. 2004, 38 (12), 2795-2809.

(51) Carter, K. E.; Farrell, J. Removal of perfluorooctane and perfluorobutane sulfonate from water via carbon adsorption and ion exchange. Sep. Sci. Technol. 2010, 45 (6), 762-767.

(52) Chularueangaksorn, P.; Tanaka, S.; Fujii, S.; Kunacheva, C. Batch and column adsorption of perfluorooctane sulfonate on anion exchange resins and granular activated carbon. J. Appl. Polym. Sci. 2014, 131 (3), 39782.

(53) Chularueangaksorn, P.; Tanaka, S.; Fujii, S.; Kunacheva, C. Adsorption of perfluorooctanoic acid (pfoa) onto anion exchange resin, non-ion exchange resin, and granular-activated carbon by batch and column. Desalin. Water Treat. 2014, 52 (34-36), 6542-6548.

(54) Caltran, I.; Heijman, S. G. J.; Shorney-Darby, H. L.; Rietveld, L. C. Impact of removal of natural organic matter from surface water by ion exchange: A case study of pilots in belgium, united kingdom and the netherlands. Sep. Purif. Technol. 2020, 247, 116974.

(55) Summers, R. S.; Kim, S. M.; Shimabuku, K.; Chae, S.-H.; Corwin, C. J. Granular activated carbon adsorption of MIB in the presence of dissolved organic matter. Water Res. 2013, 47 (10), $3507-3513$

(56) Kothawala, D. N.; Kohler, S. J.; Ostlund, A.; Wiberg, K.; Ahrens, L. Influence of dissolved organic matter concentration and composition on the removal efficiency of perfluoroalkyl substances (PFASs) during drinking water treatment. Water Res. 2017, 121, 320-328.

(57) Matsui, Y.; Knappe, D. R. U.; Iwaki, K.; Ohira, H. Pesticide adsorption by granular activated carbon adsorbers. 2. effects of pesticide and natural organic matter characteristics on pesticide breakthrough curves. Environ. Sci. Technol. 2002, 36 (15), 34323438 . 
(58) Zietzschmann, F.; Stutzer, C.; Jekel, M. Granular activated carbon adsorption of organic micro-pollutants in drinking water and treated wastewater - aligning breakthrough curves and capacities. Water Res. 2016, 92, 180-187.

(59) European Food Safety Authority. PFAS in Food: EFSA Assesses Risks and Sets Tolerable Intake; EFSA: Parma, Italy, 2020. https://www.efsa.europa.eu/en/news/pfas-food-efsa-assesses-risksand-sets-tolerable-intake (accessed 2020-11-03).

(60) Gao, Y.; Deng, S.; Du, Z.; Liu, K.; Yu, G. Adsorptive removal of emerging polyfluoroalky substances $\mathrm{F}-53 \mathrm{~B}$ and PFOS by anionexchange resin: A comparative study. J. Hazard. Mater. 2017, 323, $550-557$.

(61) Du, Z.; Deng, S.; Chen, Y.; Wang, B.; Huang, J.; Wang, Y.; Yu, G. Removal of perfluorinated carboxylates from washing wastewater of perfluorooctanesulfonyl fluoride using activated carbons and resins. J. Hazard. Mater. 2015, 286, 136-143.

(62) Montrose Environmental Group. Case Studies; ect ${ }_{2}$ : Stockholm, Sweden, 2020. https://www.ect2.com/case-studies/.

(63) Cousins, I. T.; DeWitt, J. C.; Gluge, J.; Goldenman, G.; Herzke, D.; Lohmann, R.; Miller, M.; Ng, C. A.; Scheringer, M.; Vierke, L.; Wang, Z. Strategies for grouping per- and polyfluoroalkyl substances (pfas) to protect human and environmental health. Environ. Sci.: Processes Impacts 2020, 22, 1444-1460.

(64) European Chemicals Agency. Perfluoroalkyl chemicals (PFAS); ECA: Helsinki, Finland. https://echa.europa.eu/hot-topics/ perfluoroalkyl-chemicals-pfas (accessed 2020-07-09). 